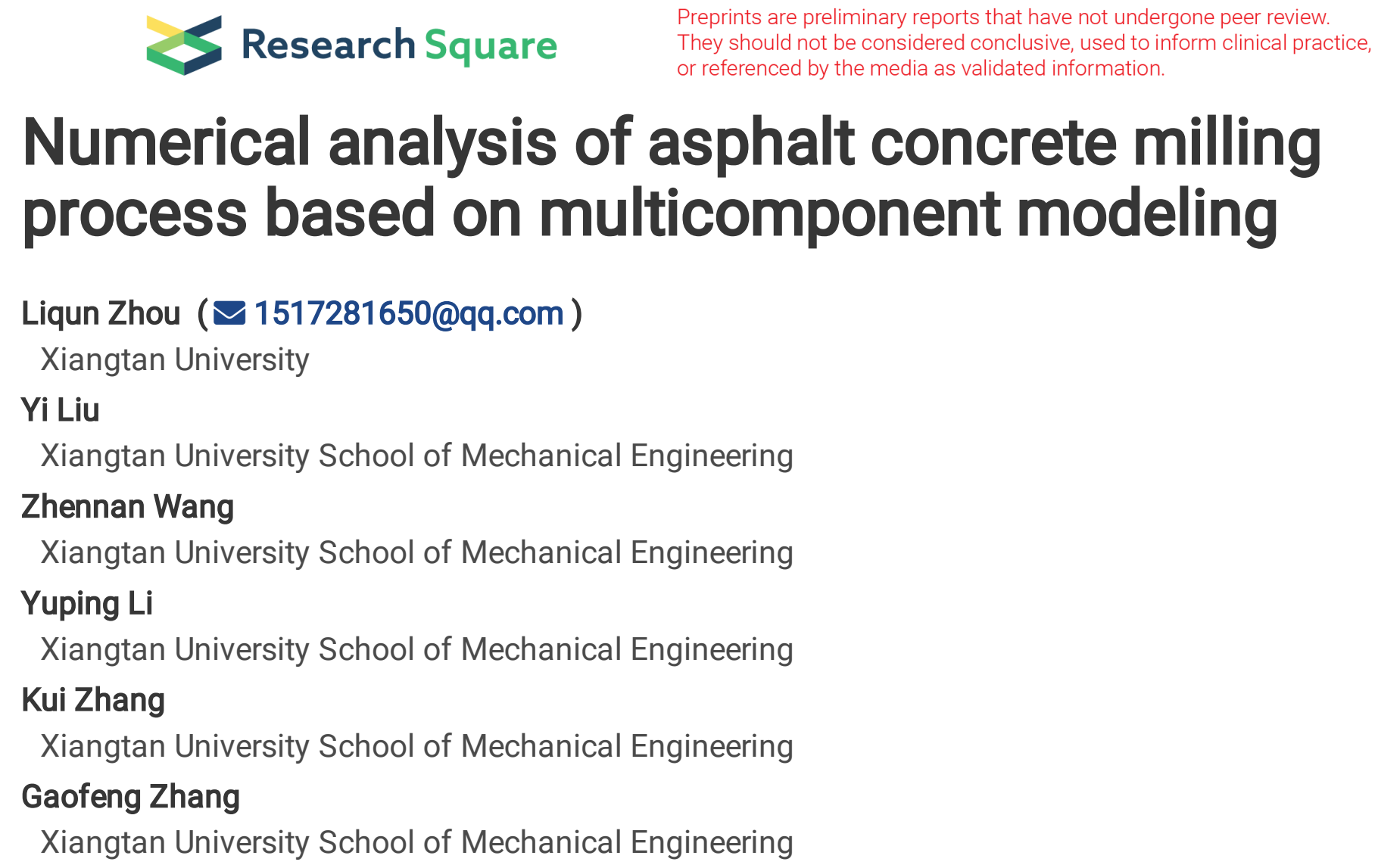

\section{Numerical analysis of asphalt concrete milling} process based on multicomponent modeling

Liqun Zhou ( $\sim 1517281650 @ q q . c o m$ )

Xiangtan University

Yi Liu

Xiangtan University School of Mechanical Engineering

Zhennan Wang

Xiangtan University School of Mechanical Engineering

\section{Yuping Li}

Xiangtan University School of Mechanical Engineering

Kui Zhang

Xiangtan University School of Mechanical Engineering

Gaofeng Zhang

Xiangtan University School of Mechanical Engineering

Original Article

Keywords: Milling planer, Asphalt concrete, Monte carlo method, Finite element analysis

Posted Date: July 9th, 2020

DOI: https://doi.org/10.21203/rs.3.rs-39326/v1

License: (c) (i) This work is licensed under a Creative Commons Attribution 4.0 International License.

Read Full License 


\title{
Numerical analysis of asphalt concrete milling process based on multicomponent modeling
}

\section{Zhou Liqun* Liu Yi Wang Zhennan Li Yuping Zhang Kui Zhang Gaofeng} Mechanical Engineering School of Xiangtan University, Xiangtan City,411105,Hunan Province, China

\begin{abstract}
In this paper, according to the different physical properties of each component of asphalt concrete, a finite element simulation is used to build a mechanical constitutive model for the concrete cutting processes. When the machine cutter contacts different aggregate particles, the variation rules of mechanical information are obtained and studied. The main research work includes: (1) The track and force of the tool in the cutting process are defined, and then the track equation of the tool tip and the calculation formula of friction resistance are obtained. The relationship between the friction resistance and working parameters is clarified. (2)From the multicompont modeling, the internal components of asphalt concrete are refined, and the mechanical properties of asphalt mortar and aggregate particles are set up. Random feeding of different aggregate particles in asphalt concrete specimens is completed by using Python software and Monte carlo method. After the simulation, the results are imported into numerical software to generate the variation curve of tool friction resistance, so as to obtain the rule of its change with various factors, and according to the above studies, the optimal working parameters combination of the milling planer are summarized.
\end{abstract}

Key words : Milling planer; Asphalt concrete; Monte carlo method; Finite element analysis

\section{Introduction}

Asphalt concrete pavement is a multiphase composite material composed of aggregate and asphalt mortar (Ref 1 ), which is widely used on highways.

Most urban roads and highways in China use asphalt concrete as pavement materials. That asphalt pavement adopts road petroleum asphalt or its processed products is determined combining with local experience (Ref 2). Under the current situation, as the total mileage of roads increases and the number of years of its use increase, the burden of road maintenance and repair work becomes heavier and heavier, so it is necessary to develop a kind of mechanical equipment at the moment to perform the work. The milling planer machine is an asphalt concrete road maintenance tool (Ref 3 ). The main function of it is to cut off the old road surface and recycle the milled asphalt waste and prepare for paving new materials (Ref 4). The throwing plate on the cutting rotor of it can be used for collecting and cutting waste while rotating and milling. It is convenient to operate and recycle the waste and reuse, has the effect of saving and *Corresponding author: Zhou Liqun, Mechanical Engineering School of Xiangtan University, 411105, Hunan Province, China. Email: 1517281650@qq.com. 
environmental protection, and is the most economical modern maintenance method at present. The passed researching method for the milling process is to consider the asphalt concrete as a monolithic homogeneous material, that is, based on the empirical method of representational theory to evaluate the mechanical properties of the mixture, and it is difficult to faithfully display the tool mechanics(Ref 3,5$)$.

The biggest problem for the planer machine in use is the uneven wear of the cutters. The uneven variation of the cutting force during the actual milling process causes abnormal wear of the tool(Ref 6,7$)$. The most accurate and effective research method in theory is to determine the cutting resistance of milling cutters by experiments. However, the cost of experimental verification is high, the time is long, and the construction of the experimental platform is complicated, which is not conducive to wide-scale promotion. At present, thanks to the rapid development of computer simulation technology, in this paper, the finite element simulation software is used to further refine the internal components of asphalt concrete from the perspective of mesomechanics, and separately set various physical parameters of asphalt mortar and coarse aggregate(Ref 8-10). The random distribution algorithm makes the distribution of aggregates in the asphalt concrete model as close as possible to the real situation(Ref 11,12). Compared with the traditional method, this study more realistically reflects the working condition of the milling machine, and has high practical value for the research and design for it.

\section{Physical property test and constitutive model selection of asphalt concrete}

\subsection{Asphalt concrete physical performance parameters}

(1) Compressive strength

Through test, the asphalt concrete compressive strength is shown in table 1 . Therefore, the average value of $4.47 \mathrm{MPa}$ is taken in the simulation.

(2) Shear strength

It can be seen from the figure 1 that the shear strength of asphalt concrete tested at room temperature varies from 0.6 MPa to $1.5 \mathrm{MPa}$, In this paper, $1.1 \mathrm{MPa}$ is taken as its shear strength value.

\subsection{Selection of asphalt concrete material model}

The Johnson-Cook model can simulate the thermo-viscoplastic deformation of asphalt concrete pavement at high strain rates, which can be expressed as:

$$
\bar{\sigma}=\left[A+B(\bar{\varepsilon})^{n}\right]\left[1+C \ln \left(\frac{\dot{\bar{\varepsilon}}}{\dot{\bar{\varepsilon}}}\right)\right]\left[1-\left(\frac{\theta-\theta_{\text {transition }}}{\theta_{\text {melt }}-\theta_{\text {transition }}}\right)^{m}\right]
$$

In the formula: 
$\bar{\sigma}$ - Equivalent plastic stress;

$\bar{\varepsilon}$ - - Equivalent plastic strain;

$\stackrel{\dot{\varepsilon}}{\varepsilon}$-Plastic strain rate;

$\dot{\overline{\varepsilon_{0}}}$ - - Initial plastic strain rate;

$\theta_{\text {melt }}-$ - Material melting temperature;

$\theta_{\text {transition }}-$ Material transition temperature;

$A-$ - Initial yield stress;

$B-$ Hardening coefficient;

C- - Strain rate coefficient;

$n$ - Work hardening coefficient;

$m-$-Temperature softening coefficient.

The parameters are set using the Johnson-Cook model, and the data is shown in the table 2 .

\subsection{Related material parameters determination}

Material parameters include tool, asphalt concrete parameters, and unit system. The tool material is 40CrNiMo hard alloy steel, and the material parameters are shown in the table 3, table 4 .

\section{Mechanical and kinematic analysis of cutting rotor and cutting process}

\subsection{Tool motion analysis}

According to the motion diagram shown in Fig. 2 and the trajectory equation of the tool 1 and the tool

2, the trajectory $K_{1} K_{1}^{\prime}$ equation of the tool 1 is:

$$
\left\{\begin{array}{l}
x_{1}=L_{1}+R \sin \delta_{1} \\
y_{1}=R \cos \delta_{1} \\
L_{1}=30 v \delta_{1} /(\pi n)
\end{array}\right.
$$

For the trajectory of tool 2 , the $K_{2} K_{2}^{\prime}$ equation is:

$$
\left\{\begin{array}{l}
x_{2}=L_{0}+L_{2}+R \sin \delta_{2} \\
y_{2}=R \cos \delta_{2} \\
L_{0}=30 v / n \\
L_{2}=30 v \delta_{2} /(\pi n)
\end{array}\right.
$$

In the formula:

$R-$ Cutting radius together with the cutter, $\quad(\mathrm{mm})$;

$v$ - Feed rate, $\quad(\mathrm{mm} / \mathrm{s})$;

$n-$ Cutting rotor speed, $(\mathrm{r} / \mathrm{min})$; 
$\delta_{1}-$ - Tool 1 rotation angle, $(\mathrm{rad}) ;$

$\delta_{2}-$ - Tool 2 rotation angle, $(\mathrm{rad})$.

The cutting thickness calculation formula is:

$$
d=\sqrt{\left(x_{2}-x_{1}\right)^{2}+\left(y_{2}-y_{1}\right)^{2}}
$$

When tool 1 completes the cut, the cut-out point coordinates are:

$$
\left\{\begin{array}{l}
x_{1}^{\prime}=30 v \delta_{1}^{\prime} /(\pi n)+\sqrt{R^{2}-y_{1}^{\prime 2}} \\
y_{1}^{\prime}=R-H
\end{array}\right.
$$

Among them, the tool 1 corner $\delta_{1}^{\prime}$ has:

$$
\delta_{1}^{\prime}=\arccos [(R-H) / R]
$$

For tool 2:

$$
\tan \delta_{2}=\left(x_{1}-L_{0}-L_{2}\right) / y_{1}
$$

In the actual working process, it is difficult to describe the variation of the cutting thickness of the tool in real time with an intuitive mathematical formula, so the average cutting thickness is usually used:

$$
\bar{d}=\frac{d_{\max }}{2}
$$

\subsection{Tool force analysis}

The force on the tool during cutting process can be divided into the compression force acted by the materials to be cut and the friction force by chip breaking off. The tool force may be decomposed into three directions: $\mathrm{X}$-direction resistance $F_{x}$, Y-direction resistance $F_{y}$ and chip flow direction friction resistance $F_{\mu}$. The $\mathrm{X}$-direction resistance $F_{x}$ is in the positive direction along the $\mathrm{X}$-axis, and the Y-direction resistance $\mathrm{F}_{\mathrm{y}}$ is in the positive direction along the Y-axis and perpendicular to the feeding direction. The resultant force can be expressed as $F_{x y}$ as shown in figure 3 ( Ref 4).

The frictional resistance of the cutter can be calculated by the following formula:

$$
F_{\mu}=\mu\left[F_{\mathrm{x}} \cos \left(\delta_{2}+\theta_{1}-\theta_{2} / 2\right)-F_{\mathrm{y}} \sin \left(\delta_{2}+\theta_{1}-\theta_{2} / 2\right)\right]
$$

In the formula, $\mu$ is the friction coefficient between asphalt concrete chips and rake face during the working process, and in this paper, $\mu=0.5$.

When the cutting thickness of the tool is $\mathrm{d}$ at a certain moment, the milling resistance moment $\mathrm{M}_{\mathrm{z}}$ can be expressed as: 


$$
\begin{aligned}
& M_{\mathrm{z}}=F_{\mathrm{x}} \cos \left(\delta_{2}\right) \cdot\left(R-\frac{2}{3} d\right)-F_{\mathrm{y}} \sin \left(\delta_{2}\right) . \\
& \left(R-\frac{2}{3} d\right)+F_{\mathrm{z}} \sin \left(\theta_{1}-\theta_{2} / 2\right) \cdot\left(R-\frac{2}{3} d\right)
\end{aligned}
$$

Most milling machine tool part of the tool head is cone, in the cutting process, the cutting area of the part in contact with the road surface is

$$
S=\frac{d^{2} \cdot \sin \left(\theta_{2} / 2\right)}{2}
$$

In conclusion, according to the above mechanical analysis of the tool, the movement trajectory of the tool tip will be affected by the working parameters. From the formula of tool friction resistance and its moment of resistance, we can get the specific values of the two, and also find that the magnitude of the two is directly related to the above three main working parameters. In this paper, the method of the controlling variables is used to study the influence of the above working parameters on the cutting of the milling machine. Among them, the cutting resistance components $F_{x}$ and $F_{y}$ in both directions can be obtained in the simulation analysis, while the rotation angle of tool 2 changes with time, but it can be obtained through geometric calculation. Thus the cutting resistance and resistance moment can be calculated by using the related data.

\subsection{Mechanical model of rotor cutting process of the milling planer}

In the process of cutting, the actual cutting resistance of the cutter is three-dimensional space force, at any time the tool cutting resistance can be broken down into the tip point trajectory tangent direction of the tangential force $\mathrm{F}_{\mathrm{y}}$, along the cutting rotor blade tool tip and the instantaneous velocity center of attachment point speed force $\mathrm{F}_{\mathrm{x}}$ and cutting rotor axis parallel to the lateral force and $\mathrm{Fz}$, as shown in figure 4 .

Due to the physical structures of asphalt concrete, the cutting resistance and cutting depth on the tool change during the cutting process with time. But the default cutting resistance of the tool at a certain moment is a fixed value, and then the XYZ coordinate system is established to decompose and analyze it in three directions. At this time, the calculation formula of cutting force $\mathrm{F}$ is:

$$
\vec{F}=F_{\mathrm{x}} \vec{i}+F_{\mathrm{y}} \vec{j}+F_{\mathrm{z}} \vec{k}
$$

In the formula, $\mathrm{i}, \mathrm{j}$ and $\mathrm{k}$ are unit vectors of $\mathrm{X}, \mathrm{Y}$ and $\mathrm{Z}$ axes.

The size of cutting resistance $\mathrm{F}$ is:

$$
F=\sqrt{F_{\mathrm{x}}^{2}+F_{\mathrm{y}}^{2}+F_{\mathrm{z}}^{2}}
$$

The force component $\mathrm{F}_{\mathrm{z}}$ parallel to the axis of the cutting rotor can significantly alleviate the 
eccentric wear of the cutter, and because the tool on the cutting rotor is symmetrically distributed, the force component can balance each other. Therefore, we mainly study the motion and mechanical rules of the tool in the XY plane, as shown in Fig. 5.

The resistance $F_{x y}$, in the XY plane will cause the tool to produce the resistance moment $M_{z}$ perpendicular to the axis of the rotor. However, in the actual working process, this resistance moment is caused by the tangential resistance F $\tau$ along the direction of the instantaneous velocity of the tool. The cutting stress on tool 2 is:

$$
\sigma=0.00418 \sqrt{\frac{E_{\Sigma}}{\rho_{\Sigma}} \cdot \frac{F_{\tau}}{d}}
$$

In the formula:

$\mathrm{F}_{\tau} \longrightarrow$ The tool tangential resistance, unit $\mathrm{N}$

$\mathrm{d}$-The tool depth of the cutter at any time in $\mathrm{mm}$

$\mathrm{E}_{\Sigma} \ldots$ The elastic modulus vector sum of the asphalt concrete and tool materials;

$\rho_{\Sigma}-$ Curvature radius of the road at the tool tip

Substituting relevant data into the equation (14), we got

$$
\begin{aligned}
& \frac{1}{E_{\Sigma}}=\frac{1}{2}\left(\frac{1-v_{1}^{2}}{E_{1}}+\frac{1-v_{2}^{2}}{E_{2}}\right) \\
& F_{\tau}=5.72 \times 10^{4} \frac{\rho_{\Sigma}}{E_{\Sigma}} d \sigma^{2}
\end{aligned}
$$

In this formula:

$v_{1} \ldots$ The asphalt concrete Poisson's ratio

$v_{2} \longrightarrow$ The Poisson's ratio of the tool material;

$\mathrm{E}_{1}$ - The elastic modulus of asphalt concrete;

$\mathrm{E}_{2}$-The elastic modulus of tool material.

Since the elastic modulus of tool material is much higher than the asphalt concrete, and the Poisson's ratio of them is small, $1-\mathrm{v} 1 \approx 1$ and $1-\mathrm{v} 2 \approx 1$, then it can be simplified into:

$$
F_{\tau}=2.86 \times 10^{4} \frac{\rho_{\Sigma}}{E_{1}} d \sigma^{2}
$$

Here $\rho_{1}$ and $\rho_{2}$ are respectively the radius of curvature of the tool and the contact point of the road surface at different times. $\rho_{1}$ is the radius of curvature at the beginning of the cutting process, which is numerically equal to the radius of the cutting rotor. 


\section{Multicomponent modeling of asphalt concrete pavement}

\subsection{The establishment of geometric model of asphalt concrete}

This section establishes a geometric model based on a XM series milling planer. The cutting radius with the tool is $350 \mathrm{~mm}$, the working parameters of the machine are shown in table 5.

In the simulated asphalt concrete model, the $\mathrm{XY}$ rectangular coordinate system is established with the intersection point of its upper surface and the right boundary as the origin. Combining with the results of the cutter mechanics and kinematics analysis, importing the trajectory equation of the second cutter into the coordinate system. The tool tip is at the lowest point of the cutting depth $\mathrm{H}=50 \mathrm{~mm}$, the coordinates of the starting position of the tool tip are $(0,-50)$; the reference point coordinate of the cutter rotation center is $(0,300)$. Fig. 6 may refer.

Asphalt concrete is considered as a uniform continuum due to traditional methods, it is difficult to study the relationship between the meso-components of asphalt concrete and the overall physical properties. Therefore, this model focuses on reflecting the microscopic structure of the internal components of the specimen, and it is a nonuniform materials cutting study.

The aggregate particles in asphalt concrete are a random distribution and arrangement inside, the specific position coordinate values of the aggregate particles are required to use the random number as a tool by the modeler, Monte Carlo algorithm (Ref 13) as a commonly used random sampling method, it has been widely used in the experiment and simulation of various random models. Python is an object-oriented dynamic type computer programming language, it is usually modeled in conjunction with ABAQUS software; using Python statements to generate random aggregates, Monte Carlo method is used to generate random numbers in a specified range at this point. Firstly generating a set of variables randomly distributed over $[0,1]$, the probability density of the unknown number $\mathrm{x}$ can be set to:

$$
f(\mathrm{x})=\left\{\begin{array}{lc}
1, & x \in[0,1] \\
0, & x \notin[0,1]
\end{array}\right.
$$

The variables distributed on $[0,1]$ are the most basic variables, and the other variables in any other interval can be transformed by it. The gradation of asphalt concrete refers to the quantitative ratio of different size particles in aggregate. Early 20th century, Fuller proposed the ideal maximum compactness gradation curve (Ref 8,9 ), the asphalt concrete prepared by the gradation determined by the curve can produce the best physical structure and strength. Fuller's parabolic equation is as follows

$$
p=100 \sqrt{\frac{D}{D_{\max }}}
$$


In the formula:

$p$ - The mass percentage of aggregate through a mesh:

$D$ - - Aggregate diameter:

$D_{\max }-$ Maximum diameter of aggregate particles:

The quantity accumulation frequency distribution of aggregate diameter $\mathrm{D}$ is:

$$
\mathrm{F}(D)=\frac{1 / D_{0}^{2} D_{0}^{1 / 2}-1 / D^{2} D^{1 / 2}}{1 / D_{0}^{2} D_{0}^{1 / 2}-1 / D_{\max }^{2} D_{\max }^{1 / 2}}
$$

Aggregate particles composed of pebbles or artificially broken limestone are irregular in appearance, but most of the asphalt concrete interface is approximately circular. Therefore, when simulating the asphalt concrete of this type of aggregate, the plane circular shape is used as the geometric model of the aggregate. For the aggregate geometric model on a two-dimensional plane, the following cumulative distribution function (Ref 6) is generally used to represent the probability of satisfying the diameter $D<D_{0}$ at any interface in asphalt concrete:

$$
\begin{aligned}
& P_{\mathrm{c}}(D<D O)=P_{k} \times\left[1.065\left(D_{0} / D_{\max }\right)^{1 / 2}\right. \\
& -0.053\left(D_{0} / D_{\max }\right)^{4} \\
& -0.012\left(D_{0} / D_{\max }\right)^{6}-0.0045\left(D_{0} / D_{\max }\right)^{8} \\
& \left.+0.025\left(D_{0} / D_{\max }\right)^{10} D_{\max }\right]
\end{aligned}
$$

In the formula:

$D_{0}$ - - Minimum diameter of aggregate particles

$D_{\max }$ - Maximum diameter of aggregate particles

$P_{\mathrm{k}}$ - - The ratio of aggregate volume to asphalt concrete volume

The maximum diameter of the aggregate particles used in this paper is $19 \mathrm{~mm}$, the smallest aggregate particle diameter is $9.5 \mathrm{~mm}$, using continuous grading, and the ratio of aggregate area to specimen size is 0.75, and the probability $P_{\mathrm{c}}$ is obtained according to formula Eq.(21), as shown in table 6 .

According to the above data and combined with Monte Carlo method, a random asphalt concrete aggregate model can be generated. The steps are as follows:

(1) Determining the spatial extent of the aggregate particles, the diameter and number of aggregate particles

(2) Using the random statement in Python, the corresponding random mathematical variables of $[0,1]$ are randomly transformed to obtain the required random variable

(3) Set the centroid coordinates to random variable values and translate the work plane to the centroid 
(4) Interference judgment is required during the aggregate delivery process. If the coordinate distance between any two aggregates is not less than the sum of the radii, it can be successfully delivered. If less than, the delivery ends and the aggregate coordinate position and radius information is regenerated.

(5) After the delivery process ends, translating the working plane to the center coordinates of each aggregate to generate circular aggregate and recording the number of aggregates.

According to the above process cycles until the number of aggregates and volume rate meeting the requirements.

In order to improve computing efficiency, non-cutting areas and cutting areas are meshed with different densities. Because asphalt mortar and aggregate particles are two different materials, therefore, the asphalt mortar and cutter in this chapter are divided by a triangular mesh, aggregate particles are meshed using quadrilateral elements; this kind of particles division can ensure relatively high analysis accuracy, bilinear displacement and temperature, just as Fig.6. The composition of each component is shown in Fig 7. Different particles are meshed with different elements.

\subsection{Material parameter settings}

Just as tables $7,8,9$.

\subsection{Asphalt concrete failure separation criteria}

The failure separation criterion determines the separation condition of the material under the cutting. The failure parameter expression is:

$$
\omega=\frac{\varepsilon_{0}^{-\mathrm{pl}}+\sum_{-\mathrm{pl}} \Delta \varepsilon^{-\mathrm{pl}}}{\varepsilon_{\mathrm{f}}^{-\mathrm{l}}}
$$

In the formula:

$\bar{\varepsilon}_{0}^{\mathrm{pl}}$ —— the initial value of the equivalent plastic strain;

$\bar{\varepsilon}^{\mathrm{pl}}-$ - Failure strain;

$\Delta \bar{\varepsilon}^{\mathrm{pl}}-$ Equivalent plastic strain.

\subsection{Define contact pairs}

In the asphalt concrete cutting process, due to the complicated internal mechanical conditions of the cutting area, a total of three sets of contact pairs was set:

(1) Aggregate-Asphalt mortar contact pairs: The interaction in the normal direction was set as the hard contact method. Setting the frictional action in the tangential direction is no friction, and allows the contact pairs to be separated from each other. Assembling the set of nodes on the asphalt mortar and 
aggregate as the first and second surfaces, respectively. The constraint way uses the motion contact method and the finite slip formula, as shown in Fig. 8.

(2) Cutting tool-Aggregate and Cutting tool-Asphalt Mortar contact pairs: The contact pairs use the surface to surface contact modes, setting the rake face and the rear face of the tool as the first surfaces, and the nodes on the asphalt mortar or aggregate as the second and third surfaces; In tangential mode, the penalty contact method is adopted as the mechanical formula; In normal mode, the interaction is also set as the hard contact method and the contact pairs are allowed to separate from each other; In restricted mode, the motion contact method and finite slip formula are used, as shown in Fig. 9.

\subsection{Set boundary conditions}

In the process of cutting simulation, the bottom of the specimen is completely fixed because there is no obvious deformation at there. The rotary center is set as the reference point of the tool RP, and the tool is specifically set as a rigid body; The cutter rotates uniformly around the RP point at the rotation center, and the rotation rate $\mathrm{n}=200 \mathrm{r} / \mathrm{min}$. Meanwhile, the cutter is given a horizontal and constant feed rate $\mathrm{v} 0=200 \mathrm{~mm} / \mathrm{s}$, as shown in Fig 10.

\section{Simulation results and processing}

Using software to simulate the cutting process, the cutting resistance of milling tool in the cutting process can be derived after all steps. In the result of display interface of ABAQUS, click generate XY direction data and select field variable output, select the cutting reference point (tool tip) on the specific tool, check the reaction force option (RF-Reaction force). In the output result, the X-direction cutting force, the Y-direction cutting force, and the cutting force resultant force are represented by RF1, RF2, and Magnitude, respectively. According to the results of the mechanics and kinematics analysis in Section 2, combined with the above data, the cutting resistance of the tool in the cutting operation can be obtained. Finally, by importing the results into MATLAB software, the working resistance value can be obtained.

\subsection{Simulation of the cutting process and cutting force}

Through the finite element modeling and analysis mentioned above, the $\mathrm{X}$ and $\mathrm{Y}$ component forces of the cutting force can be obtained. As shown in Fig. 11. The variation curves of $\mathrm{X}$ and $\mathrm{Y}$ components of cutting force received by the cutter present a parabolic distribution in general, and its value fluctuates within a certain range. MATLAB software can be used to calculate the average cutting force of the cutter in the cutting process, which $\overline{F_{\mathrm{x}}}=2547.3 \mathrm{~N}, \overline{F_{\mathrm{y}}}=572.4 \mathrm{~N}$ 。

In the cutting process, the cutting force curve fluctuates to some extent due to the collision and compression of the tool with asphalt mortar and aggregate particles respectively. By hiding asphalt mortar 
or aggregate particles respectively in ABAQUS software, only the set of particles on one of the components is extracted and the force value is derived, which can be used to deduce the force conditions when the cutter comes into contact with it alone. As shown in Fig. 12-13.

As can be seen from Fig 12, the average X-direction cutting resistance when the tool is in contact with the aggregate particle is $3748.45 \mathrm{~N}$, and the average $\mathrm{X}$-direction cutting resistance when contacting with the asphalt mortar is $2768.56 \mathrm{~N}$. These data is helpful for researching the milling planer.

According to Fig 13, the average y-direction cutting resistance when the cutter contacts with aggregate particle is $1446.34 \mathrm{~N}$, and the average y-direction cutting resistance when the cutter contacts with asphalt mortar is $884.31 \mathrm{~N}$

\subsection{Calculation of tool frictional resistance and average cutting torque}

In the section 2 , the force analysis and kinematics analysis of the cutting work of the tool have been carried out, in the cutting process, when the tool following the cutting rotor and rotates to the K2' point, the cutting thickness reaches the maximum value. At this time, the rotation angle $\delta_{2}^{\prime}$ of the tool satisfies the following formula:

$$
\left\{\begin{array}{l}
f\left(\delta_{2}^{\prime}\right)=\tan \delta_{2}^{\prime}+A \delta_{2}^{\prime}-B \\
A=\frac{30 V}{\pi n(R-H)} \\
B=\frac{\sqrt{R^{2}-(R-H)^{2}}+30 \mathrm{~V} \cdot \arccos [(R-H) / R] /(\pi n)-30 \mathrm{~V} / \mathrm{n}}{R-H}
\end{array}\right.
$$

In Eq. (23), the rotor radius $\mathrm{R}$, the cutting thickness $\mathrm{H}$, the rotor speed $\mathrm{n}$, and the feed rate $\mathrm{v}$ are all known, so the specific values of the constants A and B can be calculated. Bring the milling machine operating parameters of Table 5 into Eq. (23) :

$$
\left\{\begin{array}{l}
A=\frac{30 V}{\pi n(R-H)}=\frac{30 \times 200}{3.14 \times 200 \times(350-50)}=0.0318 \\
B=\frac{\sqrt{R^{2}-(R-H)^{2}}+30 V \times \arccos [(R-H) / R] /(\pi n)-30 V / n}{R-H}=1.488
\end{array}\right.
$$

Import tool path Eq. (25) into MATLAB software, and set the boundary conditions, let be $f\left(\delta_{2}^{\prime}\right)=0$, attainable $\delta_{2}^{\prime}=0.493$.

$$
\left\{\begin{array}{l}
x(t)=-v t-R \sin (n \pi t / 30) \\
y(t)=-R \cos (n \pi t / 30)+R-H
\end{array}\right.
$$


At the moment: $\mathrm{d}_{\max }=15.32$

The working parameters in Table 5 and the $\mathrm{X}$ and $\mathrm{Y}$ component forces of the cutting force obtained by simulation in the above are introduced into MATLAB to obtain the curve of the frictional resistance, as shown in Fig. 14.

Calculate the average frictional resistance by $\overline{F_{\mathrm{u}}}=1275.4 \mathrm{~N}$ using MATLAB software. The cutting thickness of the tool changes with time, so the average cutting thickness of the default cutting process during the calculation is $\mathrm{d}=\mathrm{dmax} / 2$; Multiplying the $\mathrm{X}$ and $\mathrm{Y}$ component forces of the cutting force by the cosine and sine of their respective angles with the tool axis, namely

$$
\overline{F_{x} \cdot \cos \left(\delta_{2}\right)}=2420.3 N \quad \overline{F_{y} \cdot \sin \left(\delta_{2}\right)}=367.6 \mathrm{~N}
$$

At this point, the average cutting torque during the work can be calculated:

$$
\begin{aligned}
& \overline{M_{\mathrm{z}}}=\left[\overline{F_{\mathrm{x}} \cdot \cos \left(\delta_{2}\right)}+\overline{F_{\mathrm{y}} \cdot \sin \left(\delta_{2}\right)}+\overline{F_{\mu}} \sin \left(\theta_{1}-\theta_{2} / 2\right)\right] \cdot\left(R-d_{\max } / 3\right) \\
& =1113.62 \mathrm{~N} \cdot \mathrm{m}
\end{aligned}
$$

This value is close to the relevant test calculation data.

\subsection{Effect of cutting rotor speed $n$ on the cutting process}

The cutting process was simulated according to the Working parameters in Table 10, results please to see Fig 15. From the figure, we know that the maximum cutting stress reached 408MPa. The cutting surface morphology is shown in Fig.16. From the figure, we know that during the cutting process the aggregate and the mortar particles are cut apart. This is useful for us to realize the cutting process. The cutting force curves of the tool in the $\mathrm{X}$ and Y directions during cutting are shown in Figures 17 and 18. According to Eq. (9) and (10), the values of the cutting force and the average moment received by the tool at different cutting rotor speeds can be calculated, as shown in table 11 .

According to the simulation results, it can be concluded that when the cutting rotor speed $\mathrm{n}$ increases within a certain range, the cutting force condition of the tool and its value are reduced to some extent. For each 50r/min increase in cutting rotor speed, the corresponding average frictional resistance decreases by $3 \%-9 \%$, the average cutting force torque decreases by $2 \%-8 \%$, and the specific energy consumption coefficient decreases by $5.4 \%-9.8 \%$. Because the micro-mechanical method is used to reflect the internal structure of asphalt concrete, the cutting force will be abrupt when the tool contacts the aggregate particles during the cutting process, such as in Fig.17 18.

\subsection{Effect of cutting depth $H$ on the cutting process}

The cutting process was simulated according to the operating parameters in Table 12 . The cutting force curves of the tool in the $\mathrm{X}$ and $\mathrm{Y}$ directions during cutting are shown in Figs.19 and 20. According to 
the Eq. (9) and (10), the values of the cutting force and the average cutting torque received by the tool at different depths of cut can be calculated, as shown in table 13.

According to the simulation results, it can be concluded that when the cutting depth $\mathrm{H}$ increases within a certain range, the cutting force value of the tool will increase to a certain extent. For each $10 \mathrm{~mm}$ increase in cutting depth, the corresponding average cutting force increases by $9.3 \%-22.1 \%$, the average milling torque increases by $18 \%-25 \%$, and the specific energy consumption coefficient increases by $6.8 \%-29 \%$. It can be seen that the frictional resistance of the tool is positively correlated with the depth of cut, and the growth rate is accelerated after the depth exceeds $50 \mathrm{~mm}$.

\subsection{The influence of feed rate $v$ on the cutting process}

The cutting process is simulated according to the working parameters in table 14. In the cutting process, the cutting force curves of the tool in the $\mathrm{X}$ and $\mathrm{Y}$ directions can be calculated. According to Eq. (9) and (10), the values of the cutting force, frictional resistance and average cutting torque received by the tool at different feed rates can be calculated, as shown in table 15. The working process at different feed rates is shown in the figure 21 .

According to the simulation results, it can be concluded that when the feed rate $\mathrm{v}$ increases within a certain range, the cutting force and its value of the cutter also increase. For each step increase in feed rate, the average frictional resistance of the tool increases by $13.3 \%-5.3 \%$, the average cutting torque increases by $3 \%-6.2 \%$, and the specific energy dissipation coefficient increases by $1.1 \%-6.3 \%$.

\section{Data analysis and discussion}

According to the numerical simulation of the cutting process under several groups different working parameters, and the calculation and comparison of the data, we got the information that the data may be used to judge the degree of the tool wear and the variation trend of cutting force of the milling machine.

According to the results of the tables 11 to 15 , the cutting force received by the tool in the working process is directly related to the working parameters of the feed rate, the rotational speed and the cutting depth, such as table 16, so the value of the cutting force can be used as the criterion for determining the degree of tool wear. According to Fig. 17 to 21, in the three physical quantities of the X-direction average cutting force $F_{x}$, the $Y$-direction average cutting force $F_{y}$, and the average frictional resistance $F_{\mu}$, the value of the Y-direction average cutting force $F_{y}$ is relatively stable, and is least affected by the changes of three working parameters. So it is not suitable used as the basis for determining the degree of the tool wear; The $\mathrm{X}$-direction average cutting force $\mathrm{F}_{\mathrm{x}}$ is most obviously affected by the change of the working parameters, but considering its always along the direction of the milling machine feed rate, it can't affect the direction 
of the force on the contact surface of the tool and the road materials. A situation that changes over time; and the average frictional resistance is $F_{\mu}$ in the direction of the cutting waste flowing out of the tool rake face at any time, and the coordinate system of the force always follows the movement of the tool; this chapter regards the average frictional resistance of the tool as its wear criterion. The correlation between the average frictional resistance $F_{\mu}$ and the parameter level is shown in Fig. 22.

Fig. 22 visually shows the influence trend of the feeding rate $v$, cutting speed $n$ and cutting depth $H$ on the average friction resistance in the cutting process of the milling machine, and then the wear condition of the cutter under different working parameters can be analyzed according to the numerical value of the average friction resistance. The main problems in use for the milling machine are the wear of the tools. When the rotor speed $\mathrm{n}$ and the cutting depth $\mathrm{H}$ are constant, the average frictional resistance $\mathrm{F}_{\mu}$ is positively correlated with the feed rate $\mathrm{v}$, but the increase range is limited, so the parameter level curve corresponding to the feed rate is positively correlated; It can be seen that when the cutting depth is increased from $50 \mathrm{~mm}$ to $60 \mathrm{~mm}$, the curve is steep, indicating that the increase of friction resistance is accelerated at the same time.

According to the conclusion of the above data processing, in order to improve the wear condition, a higher cutting rotor speed $\mathrm{n}$ and an appropriate cutting depth $\mathrm{H}$ should be preferred, and the feed rate can be determined according to actual construction requirements.

Fig.23 shows the variation trend of specific energy dissipation coefficient $\gamma$ with parameter grade. It can be seen from the figure that the coefficient $\gamma$ is negatively correlated with the rotating speed of the cutting rotor, but positively correlated with the feeding rate and cutting depth of the milling machine, especially the increase of cutting depth will make the specific energy dissipation coefficient $\gamma$ rise rapidly.

In the process of theoretical analysis, reducing the feed rate $\mathrm{v}$ and cutting depth $\mathrm{H}$ can help to reduce the tool wear, but this inevitably reduces the work efficiency of the milling machine and thus causes the construction period delay. Higher rotational speed can appropriately reduce cutting force and alleviate wear, but working at a higher rotational speed may cause the machine great vibrations. So it is not advisable to increase the rotational speed of the cutting rotor blindly. Therefore, according to the gradient changes of each working parameter corresponding to the four parameter levels, the optimal combination of working parameters is summarized, as shown in table 17.

\section{Conclusions}

In this paper, Python software is combined with Monte Carlo algorithm to complete the random 
feeding of aggregate particle in asphalt concrete milling process. The simulation model of the working process is established by ABAQUS and its numerical analysis and research are carried out. The research idea of meso-mechanics is used in the model. Through the control variable method, the influence of the main working parameters of the milling planer on the cutting performance of the cutter is studied. The $\mathrm{X}$-direction and Y-direction component values of the cutting resistance of the tool can be directly obtained through the simulation process. Combined with the relevant formulas derived from the cutter motion and mechanical analysis, the values of frictional resistance and resistance moment suffered by the cutter during the cutting process can be calculated in MATLAB software. It is comprehensively analyzed the influence of various working parameters on the cutting performance of the cutter and finally it is transformed into a more intuitive figures to study their respective trends. Finally, a more appropriate set of working data is summarized.

Availability of data and materials

The data and materials that support the plots within this paper and other findings of this study are available from the corresponding author upon reasonable request.

Competing interests

The authors declare no competing interests.

Funding

Not applicable.

Authors' contributions

ZLQ and ZK were responsible for the literature survey, structure arrangement and paper writing; LYP and ZGF designed the experiments and performed; LY performed the multicomponent modeling; WZN performed the numerical analysis. All authors read and approved the final manuscript.

Acknowledgements

Not applicable 


\section{References:}

1. Ministry of transport of the people's republic of China. (2006). JTGD50-2006 Specifications for Design of Highway Asphalt Pavement. China Communications Press, China. (in Chinese)

2. He Zhaoyi, Wang Zongmin, Zhu Lei, et al. (2010). Rutting Caculaiton of Asphalt Pavement Based on the Johnson-Cook Viscoelastic Model. Journal of Chongqing Jiaotong University (Natural Science), 29(1), 49-53.

3. Zhou Liqun, Chen Xi, Li Yu-ping, Xu Xin. (2019). Numerical Simulation of Vibration-assisted Machining of Asphalt Concrete Based on Finite Element Method. Mining and Metallurgical Engineering, 39(4), 136-139, 144.

4. Zhou Liqun, Xu Xin, Guan Hanqing, Song Guangheng, Li Yuping. (2017). Numerical Simulation of Vibration Cutting for Asphalt Concrete Paving Based on Discrete Element Method. Journal of Mechanical Engineering, 53(22), 166-175.

5. Menezes P.L., Lovell M.R., Avdeev I.V., et al. (2014). Studies on the formation of discontinuous chips during rock cutting using an explicit finite element model. International Journal of Advanced Manufacturing Technology, 70(1-4), 635-648.

6. Menezes P.L. (2017). Influence of cutter velocity, friction coefficient and rake angle on the formation of discontinuous rock fragments during rock cutting process. International Journal of Advanced Manufacturing Technology, 90, 3811-3827.

7. Turchetta S. (2012). Cutting force and diamond tool wear in stone machining. International Journal of Advanced Manufacturing Technology, 61(5-8), 441-448.

8. Liu Guangting, Gao Zhengguo. (2003). Random 3-D aggregate structure for concrete. Journal of Tsinghua University (Science and Technology), 43(8), 1120-1123.

9. Liu Guangting, Wang Zongmin. (1996). Numerical simulation study of fracture of concrete materials using random aggregate model. Journal of Tsinghua University (Science and Technology), 36(1), 84-89.

10. Hanifi B., Tahir S., Orhan A.,Hasan K.. (2008). Durability of concrete made with granite and marbleas recycle aggregates. Journal of Materials Processing Technology, 208, 299-308.

11. Rong Mingda, Guo Zhiyong, Wu Xueqian. (2017). Establish Random Aggregate Model Based on Monte-Carlo by ANSYS. Construction Machinery Technology and Management, (11): 71-73.

12. Bai Wei, Peng Gang. (2007). Monte-Carlo Method Aggregate Random Structures for Concretes by ANSYS. Journal of Shihezi University (Natural Science), 25(4), 504-507.

13. Xu Zhongji. (1985). Monte Carlo method. Shanghai Science and Technology Press, China. (in Chinese). 
Figures

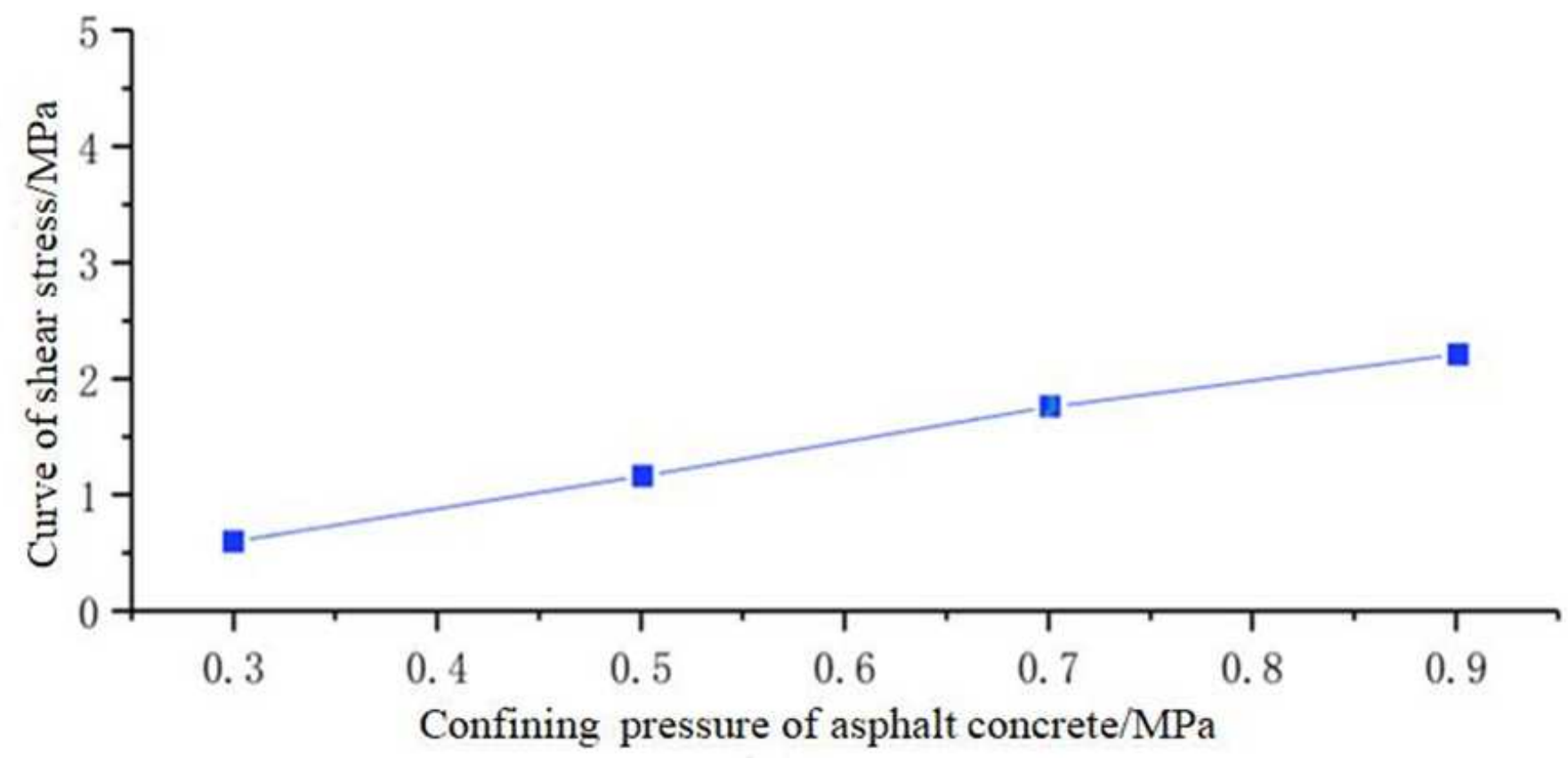

\section{Figure 1}

The curve of shear stress and confining pressure of asphalt concrete 


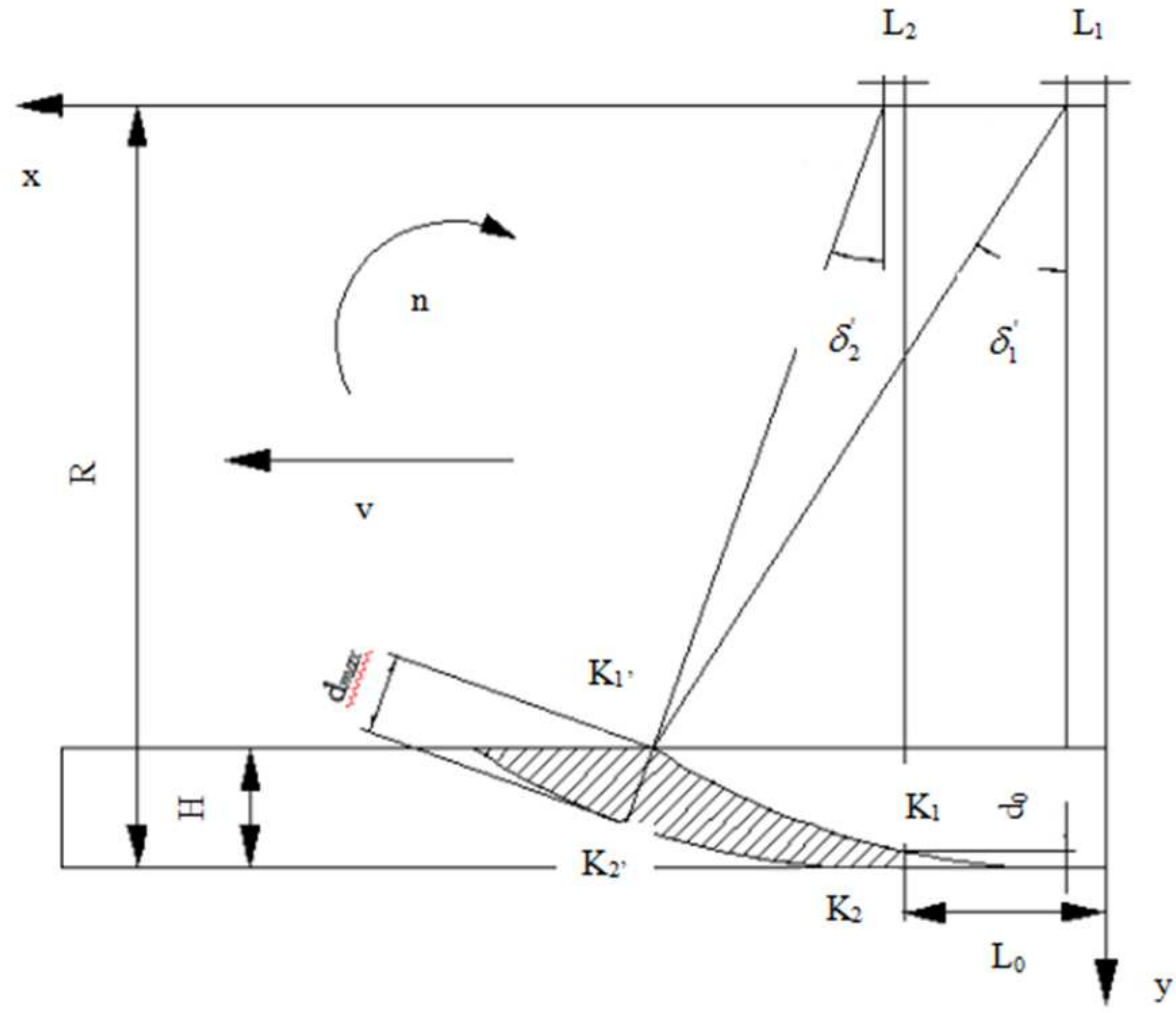

Figure 2

Cutting path of the before and after two tools 


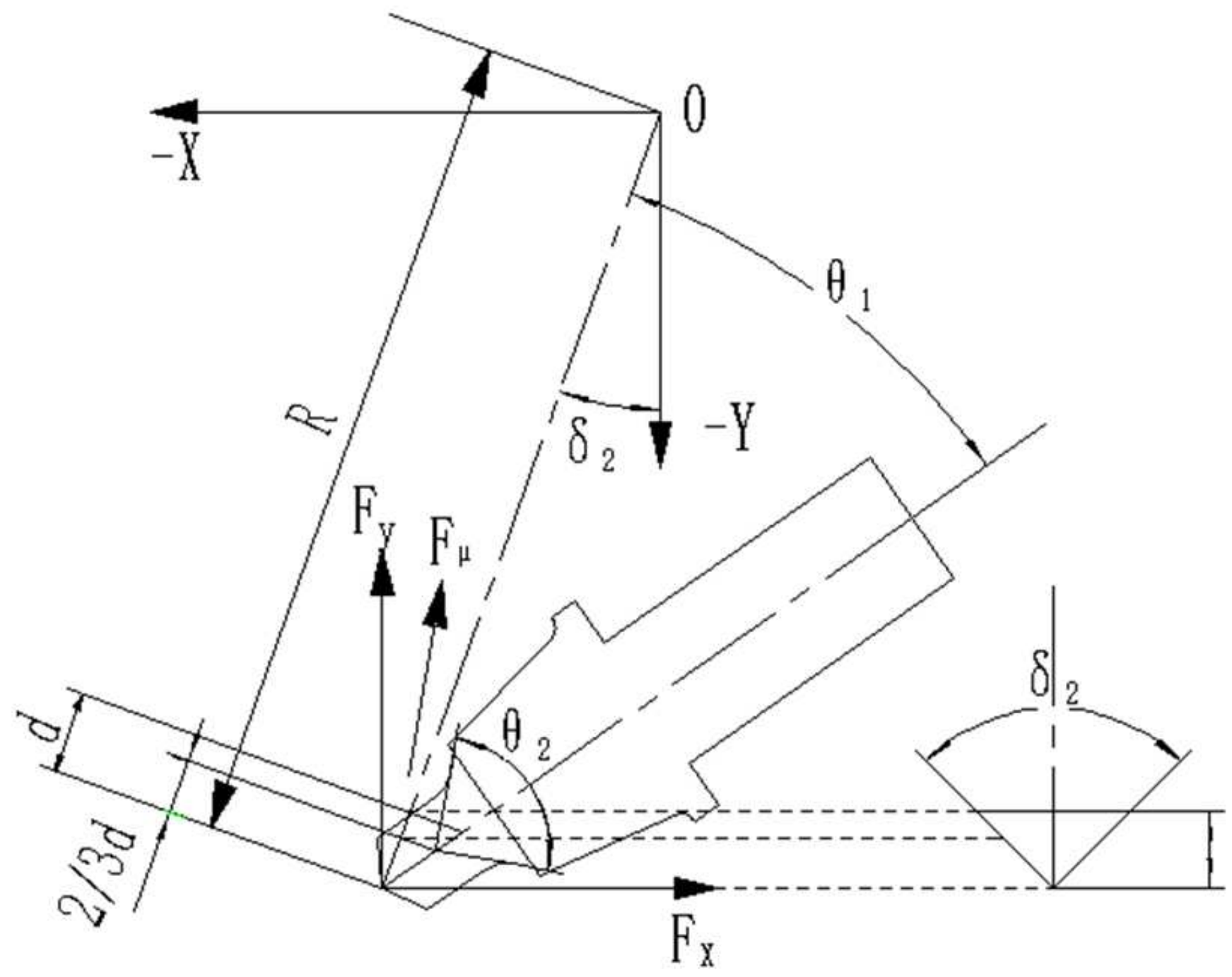

Figure 3

Tool force analysis diagram 


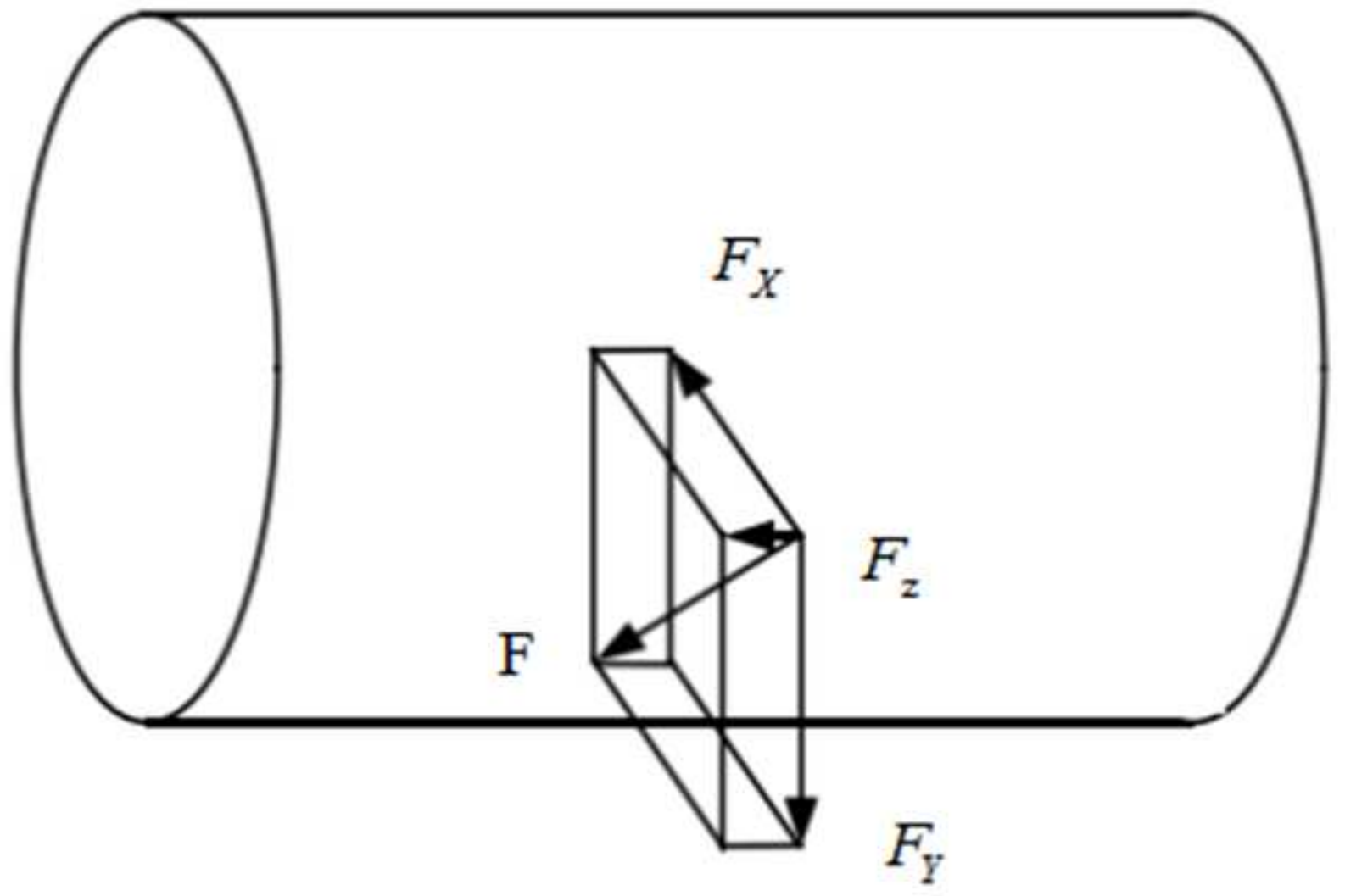

Figure 4

The analysis diagram of tool force on cutting rotor 


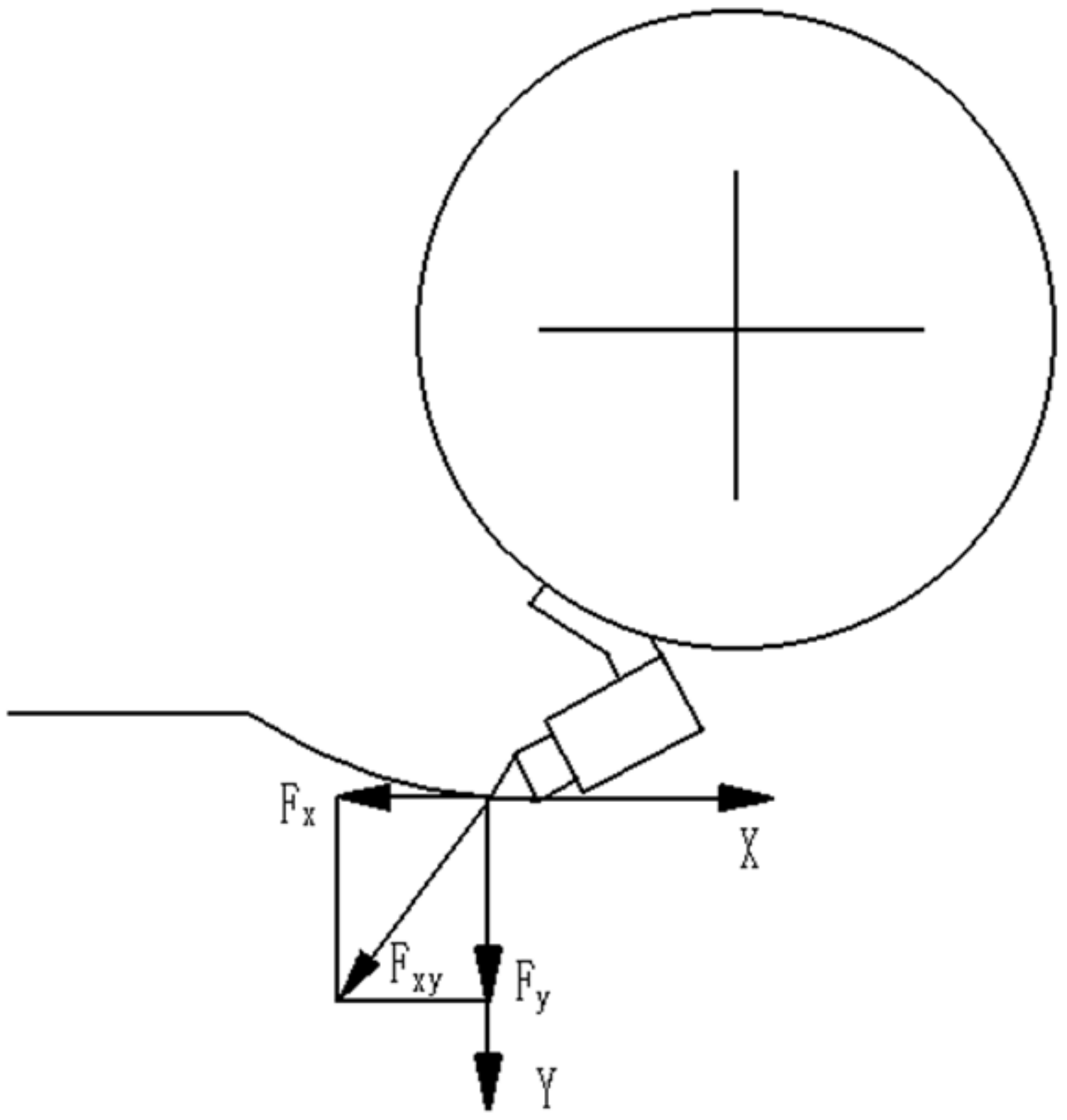

Figure 5

The cutting rotor on $\mathrm{XY}$ section force 


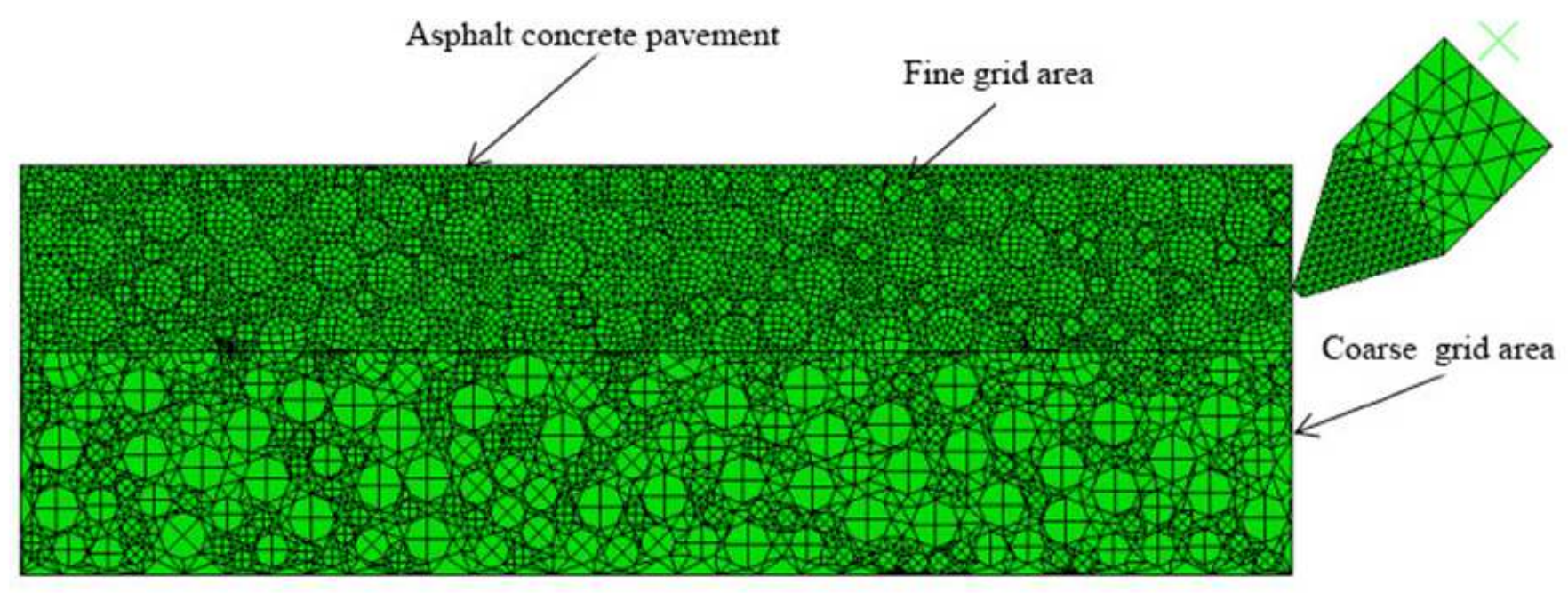

Figure 6

Meshing of the cutting process model

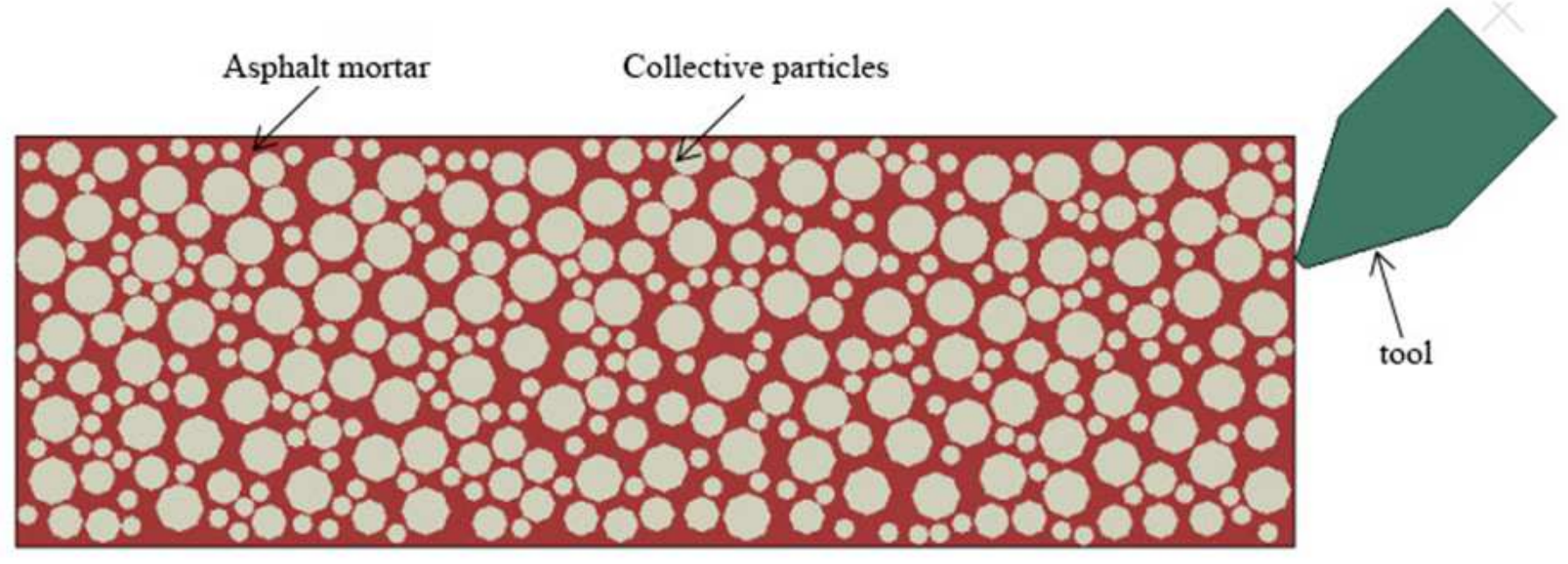

Figure 7

Material model of each component in the cutting model 


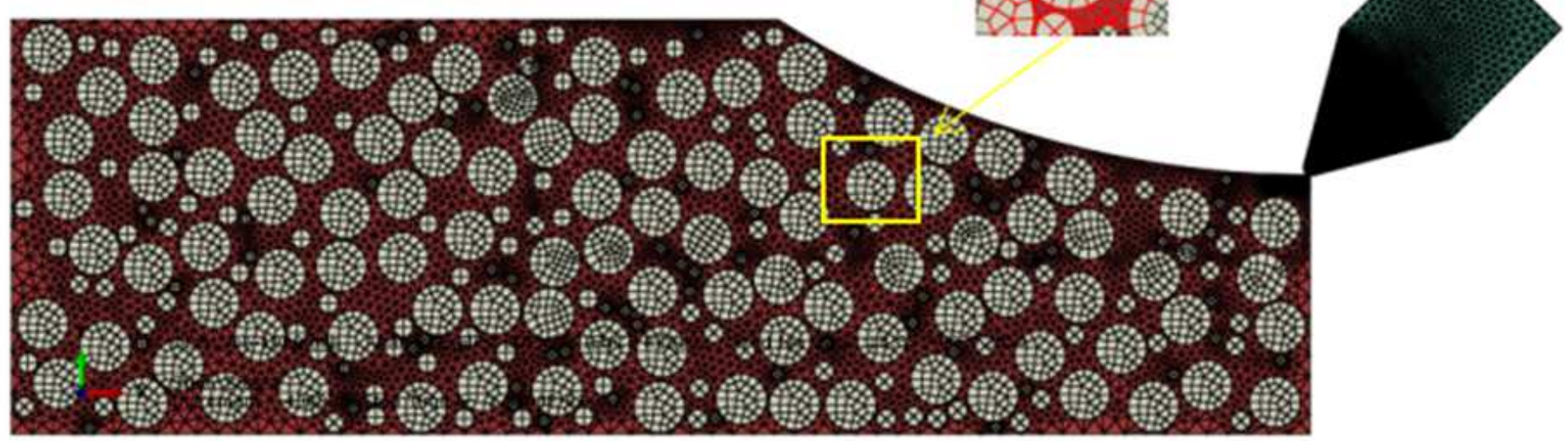

\section{Figure 8}

The contact pairs of the pavement materials

The second surface

The third surface

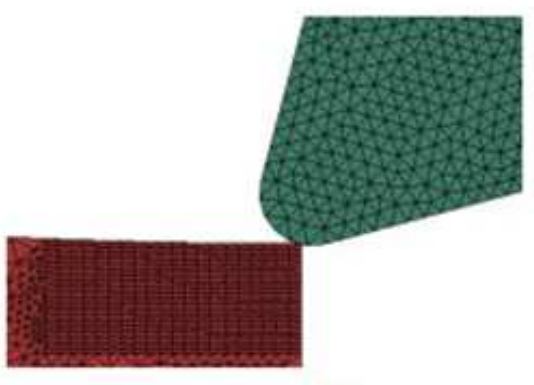

The first surface

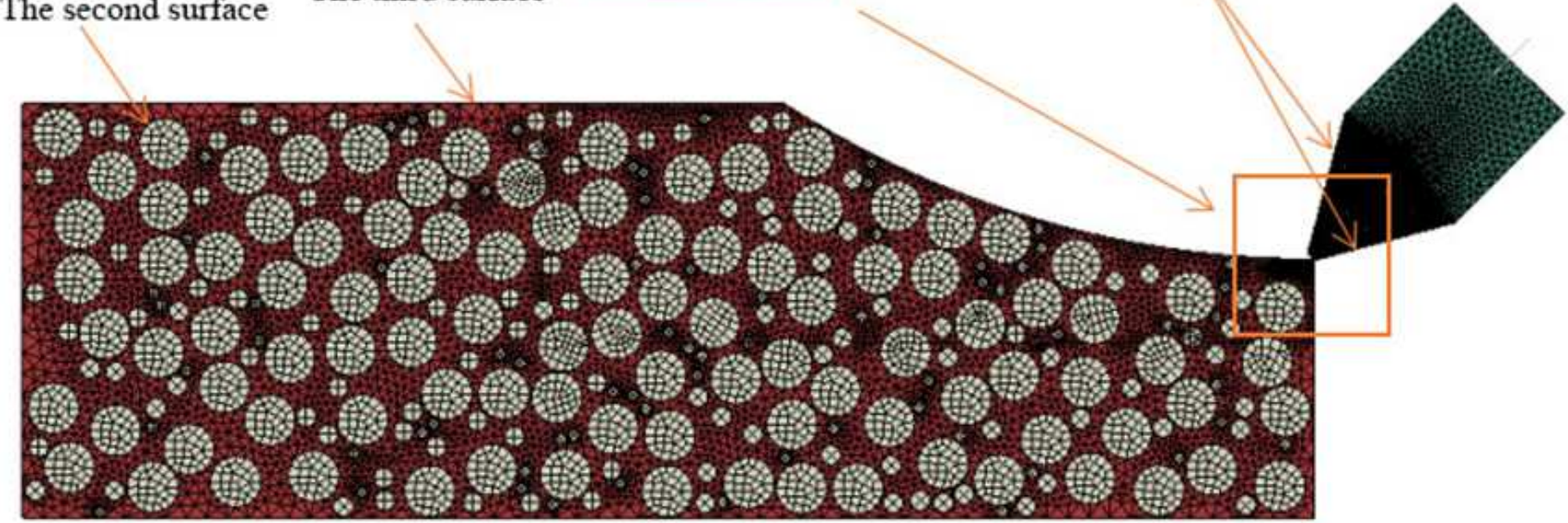

Figure 9

Contact pairs of the cutter with asphalt mortar and aggregate particles 
Give the tool horizontal speed and speed to the left $\longleftarrow$

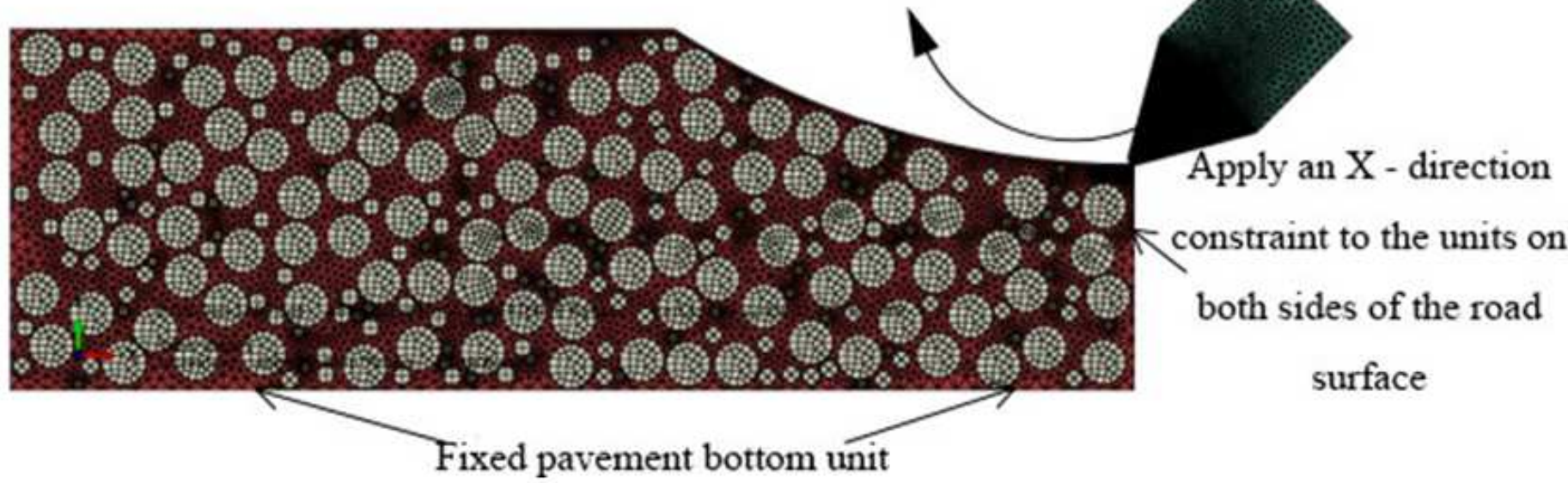

Figure 10

Boundary conditions and constraints are imposed on the road surface and the tool

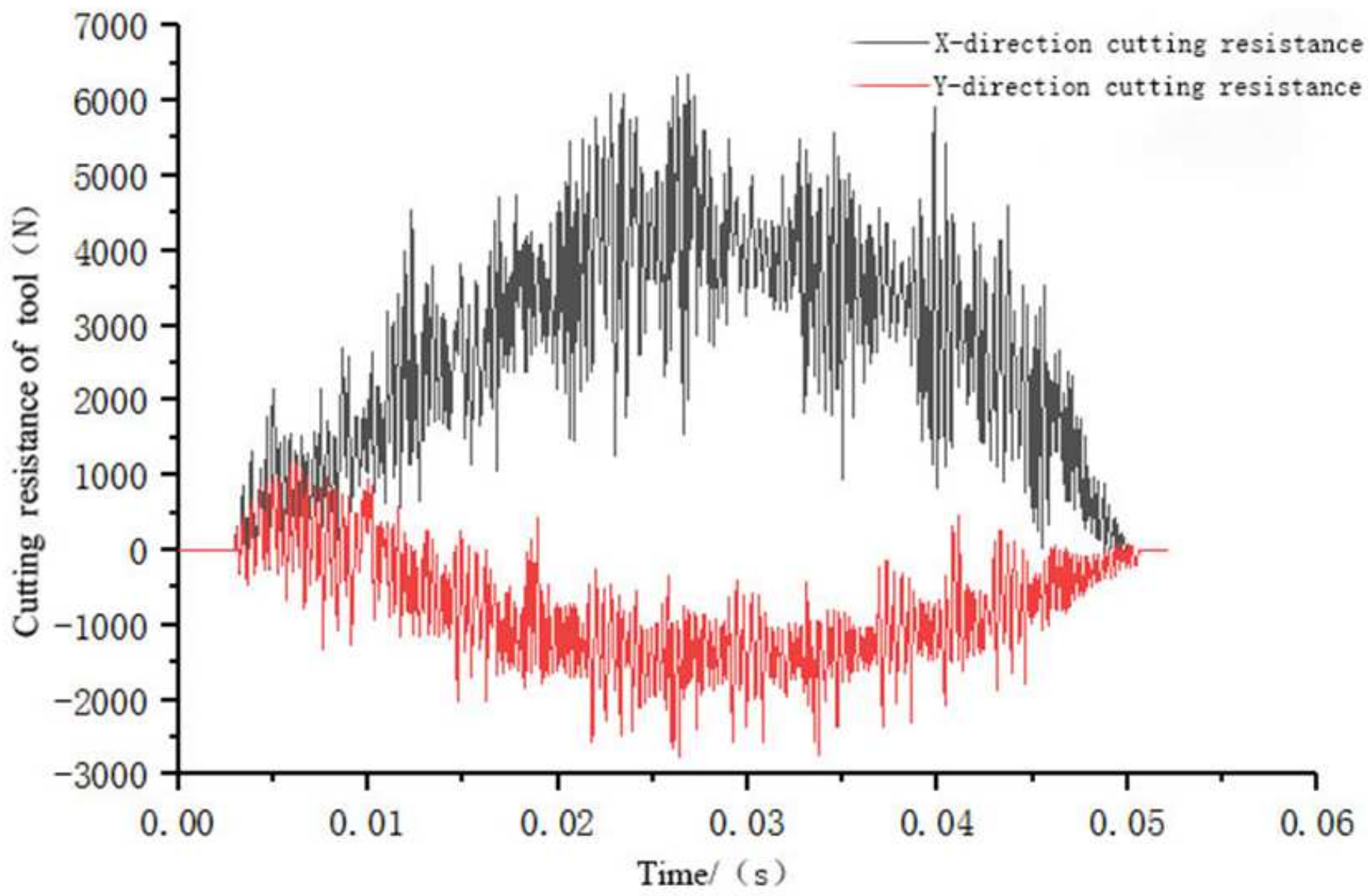


Figure 11

The curve of $X$ and $Y$ components of cutting force

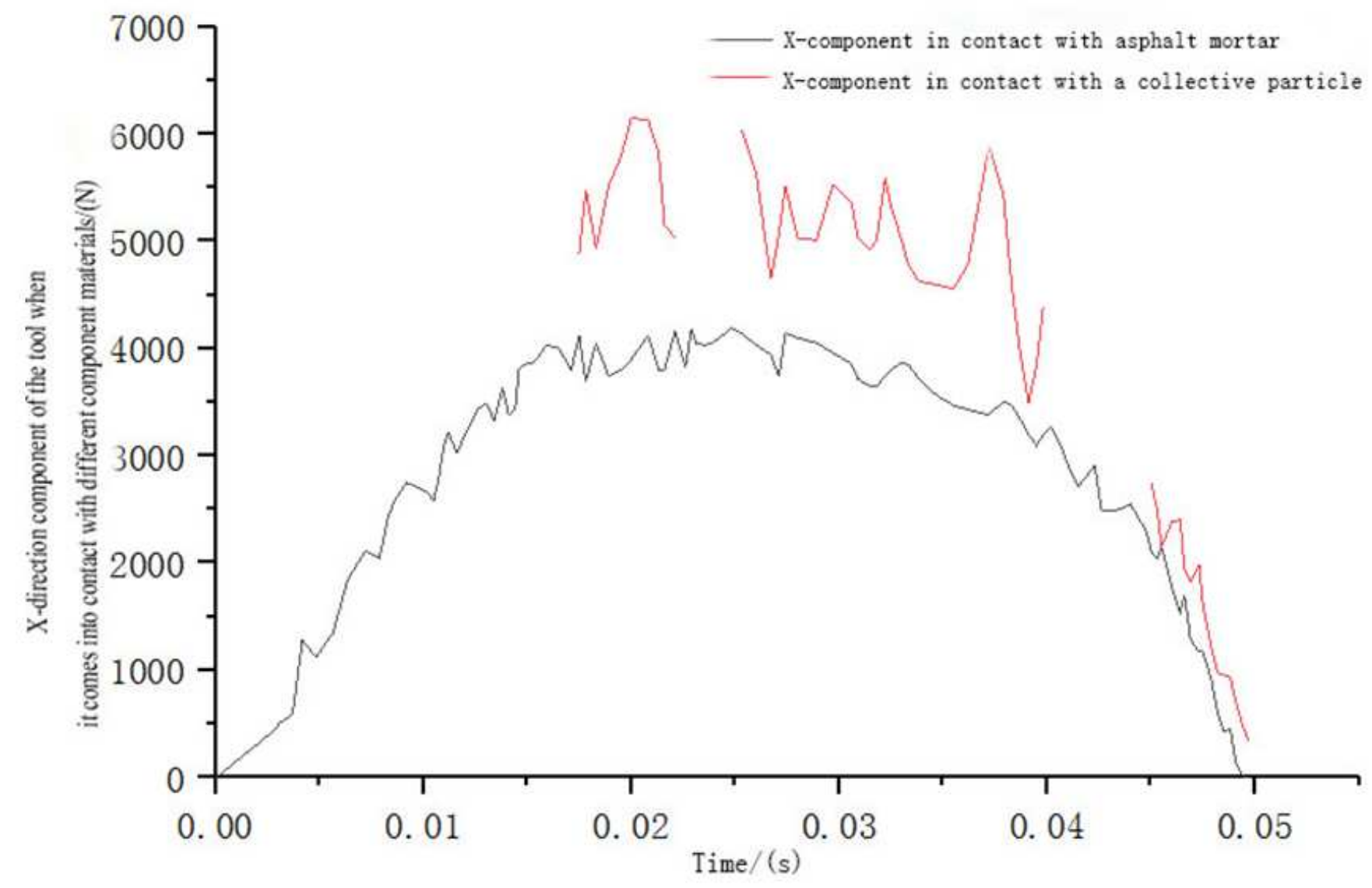

Figure 12

$\mathrm{X}$ - direction curve of cutting force in contact with different components 


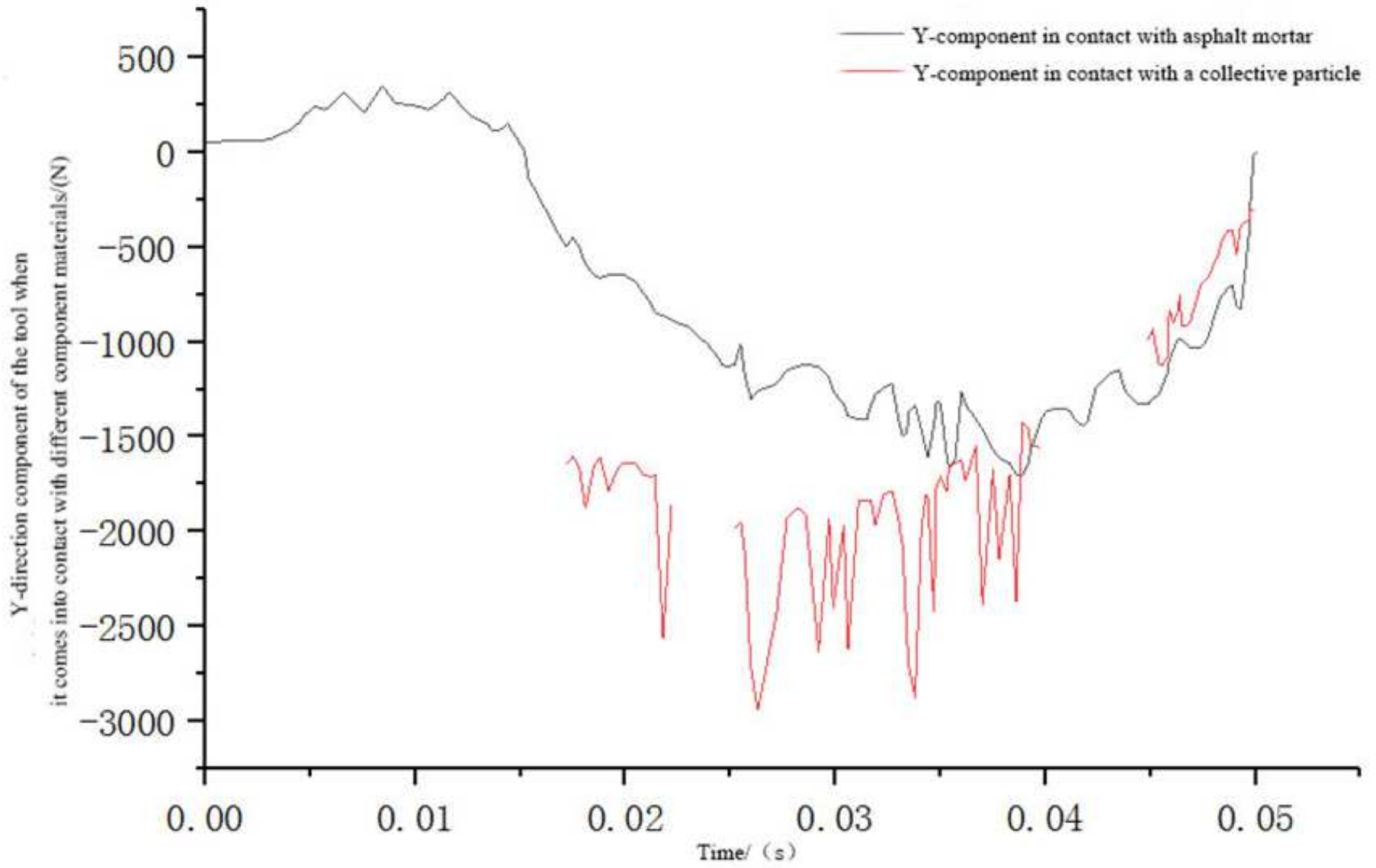

Figure 13

The variation curves of cutting force in $Y$ direction when the cutter is in contact with different components 


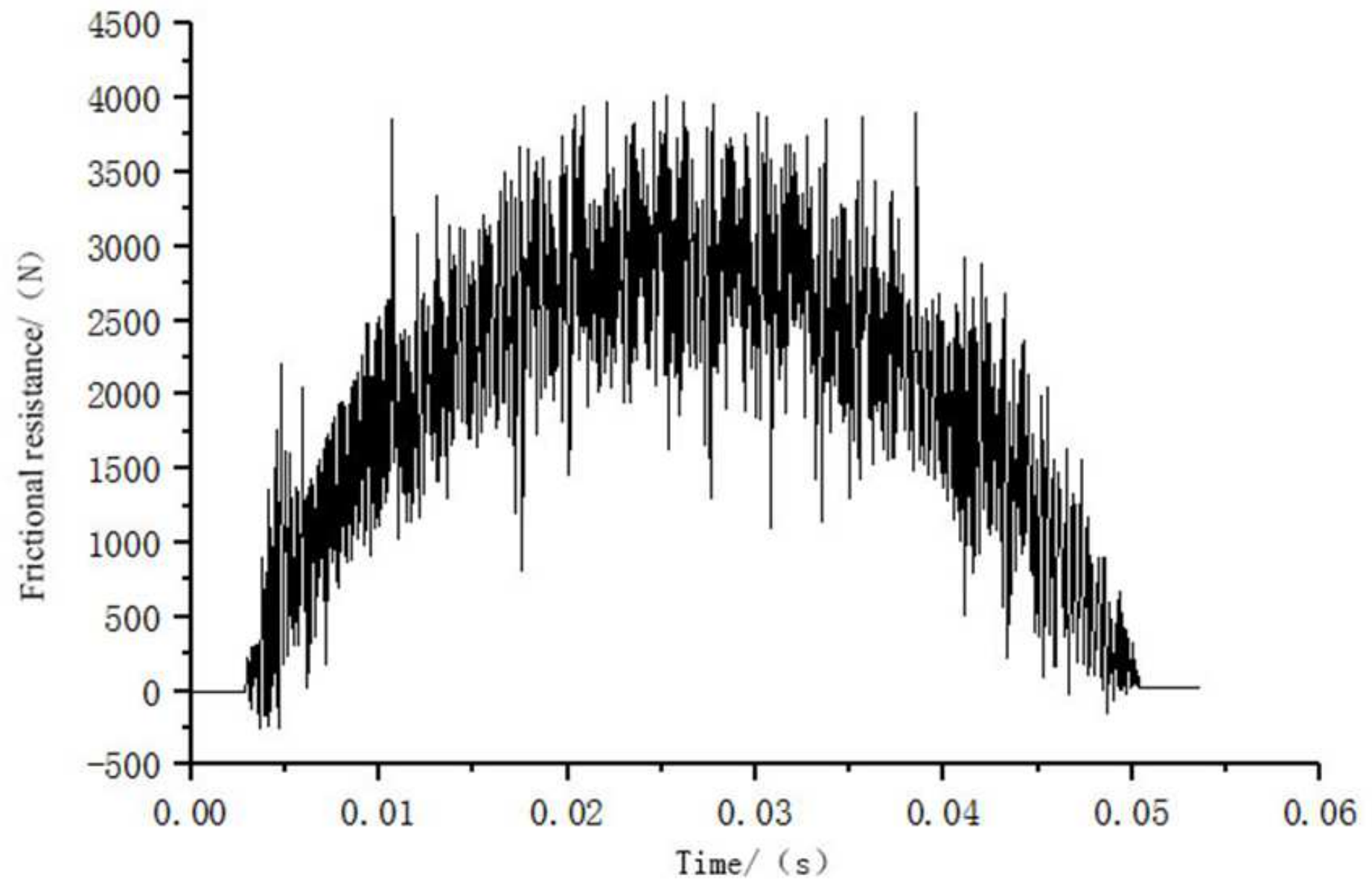

Figure 14

Friction resistance curve 

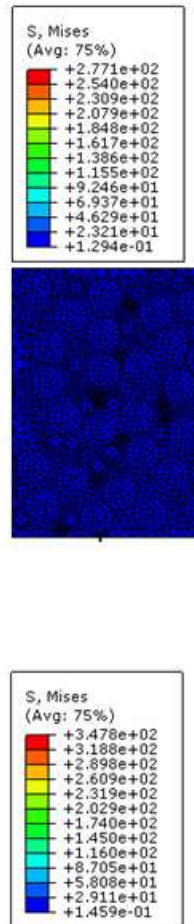

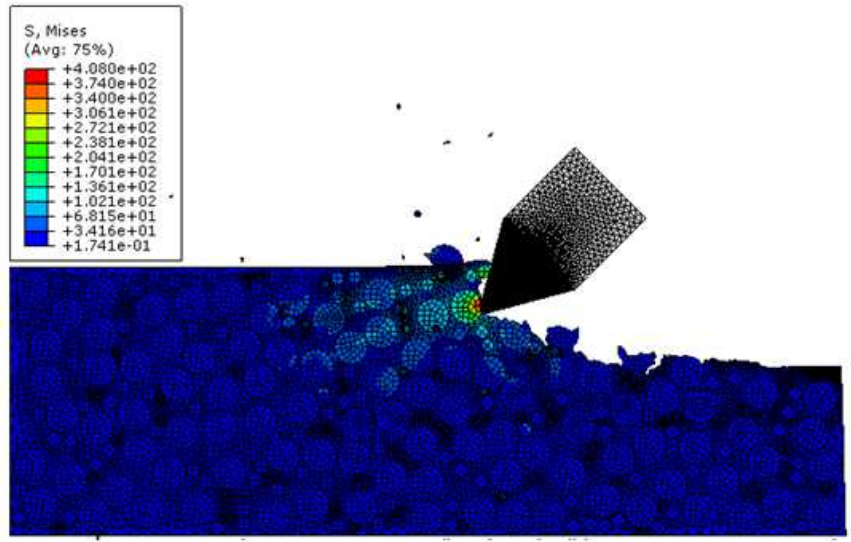

(c)

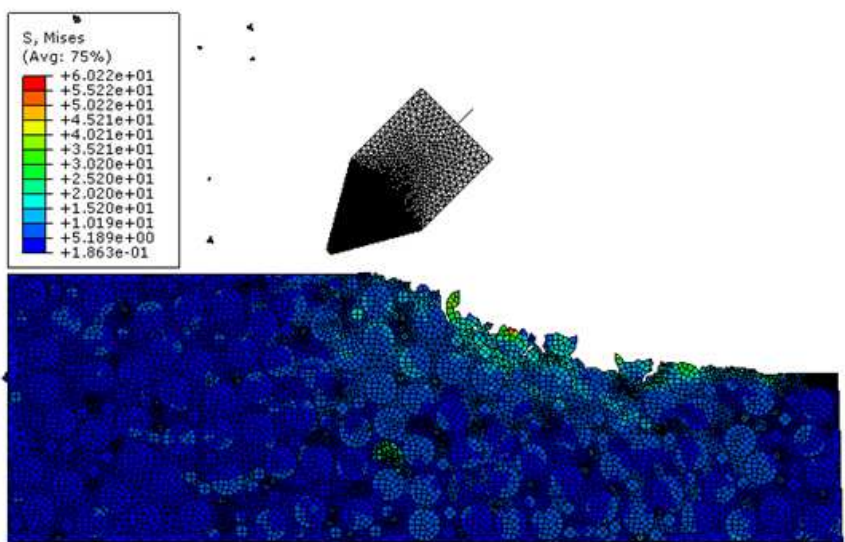

(d)

\section{Figure 15}

Cutting process stress nephogram: (a) $t=0.01 \mathrm{~s}$, (b) $t=0.02 \mathrm{~s}$, (c) $t=0.03 \mathrm{~s},(d) t=0.04 \mathrm{~s}$

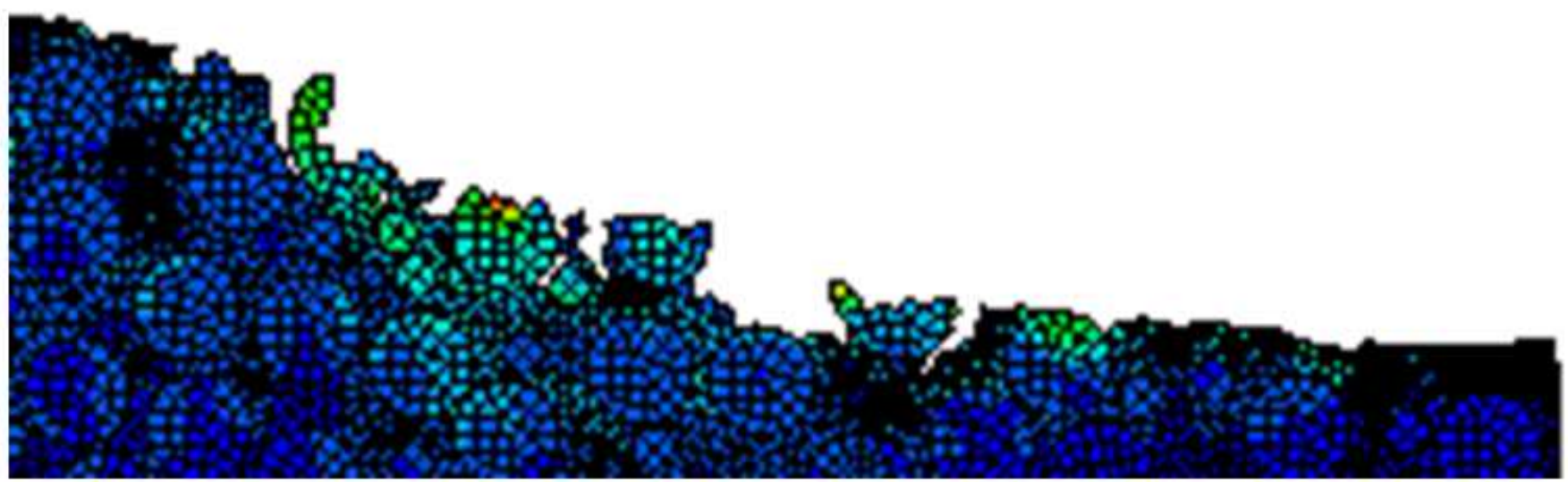

Figure 16 


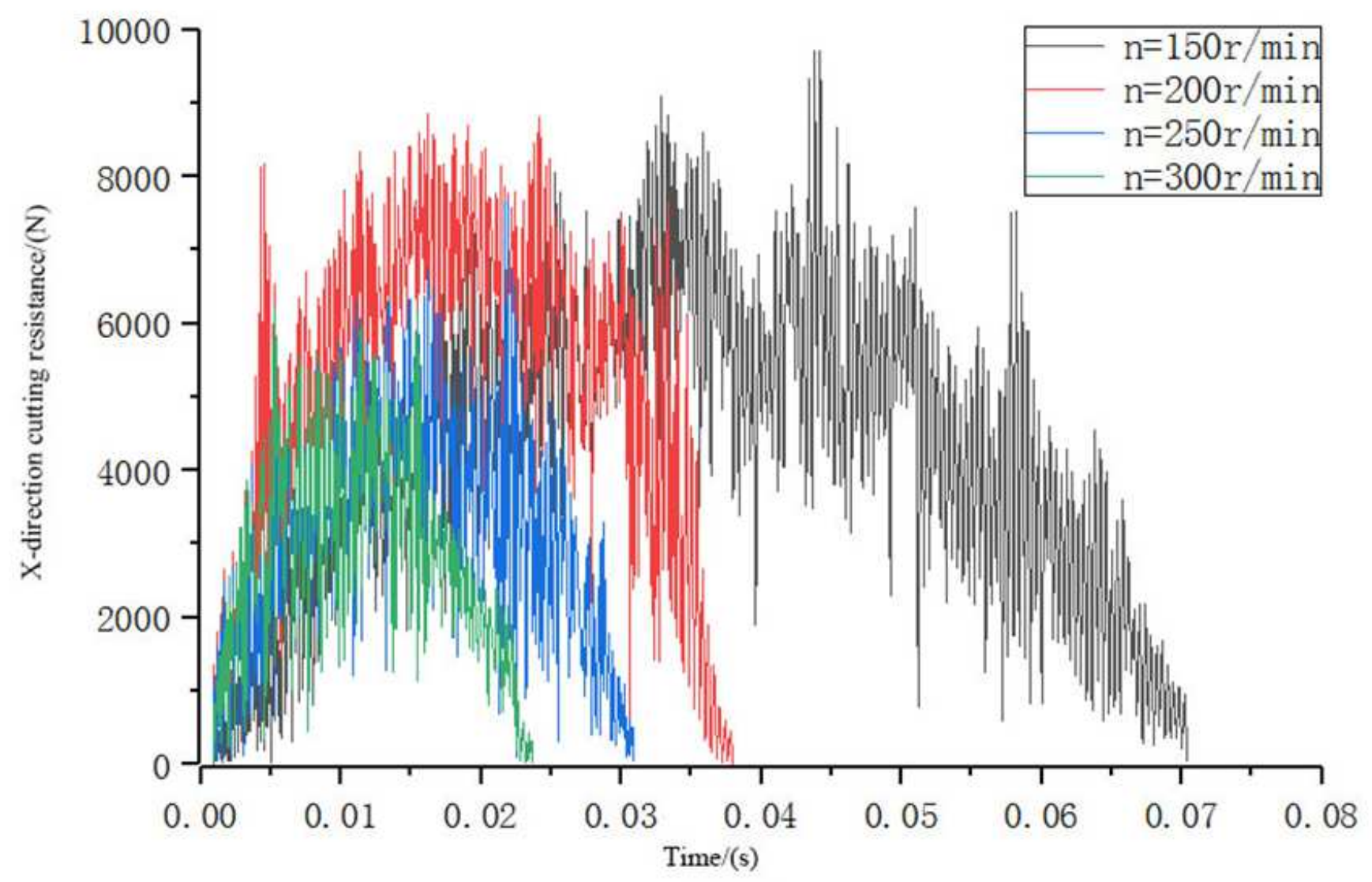

Figure 17

X-direction cutting force at different speeds 


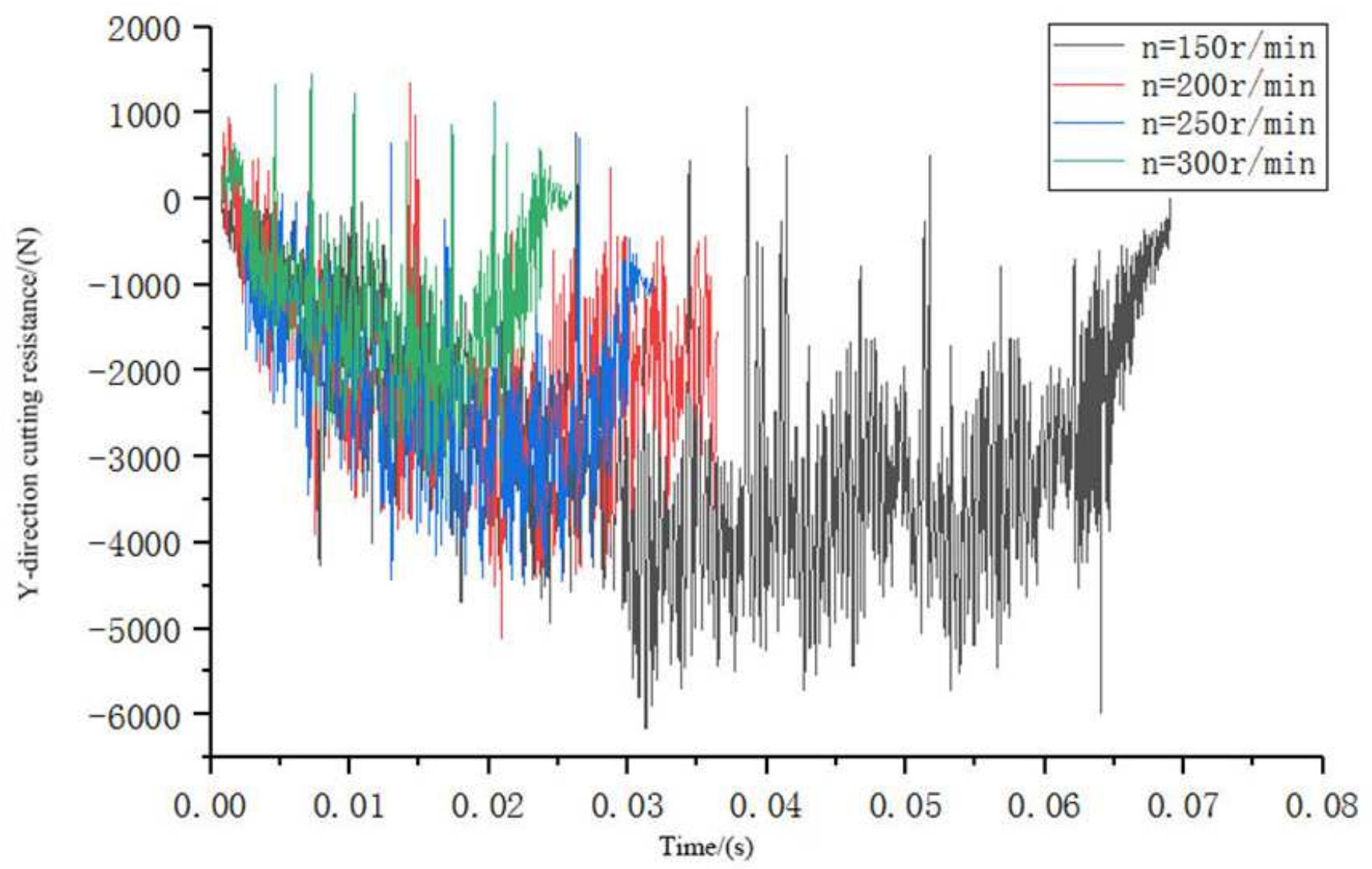

Figure 18

Y-direction cutting force at different speeds 


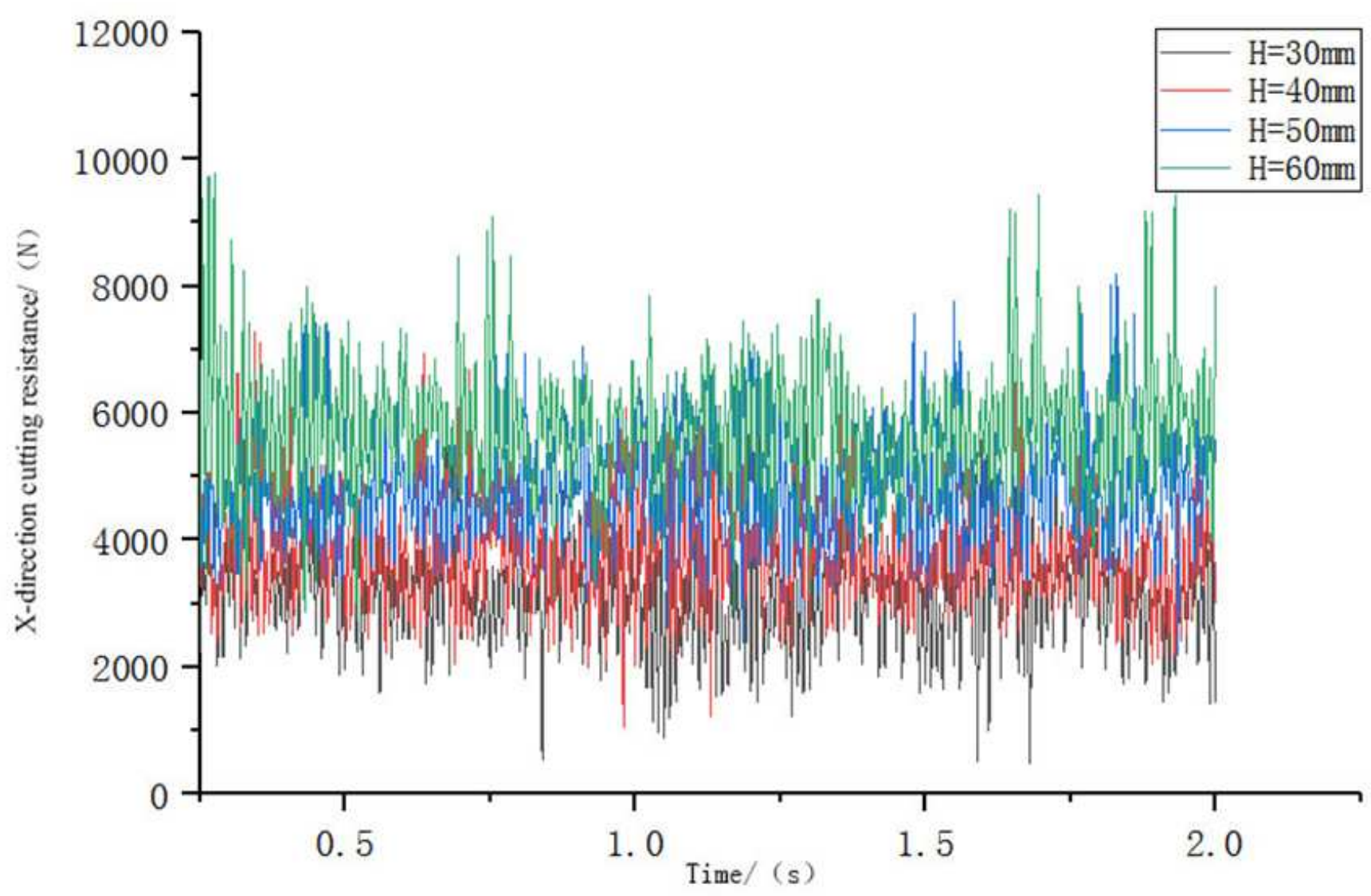

Figure 19

X-direction cutting force at different depths of cut 


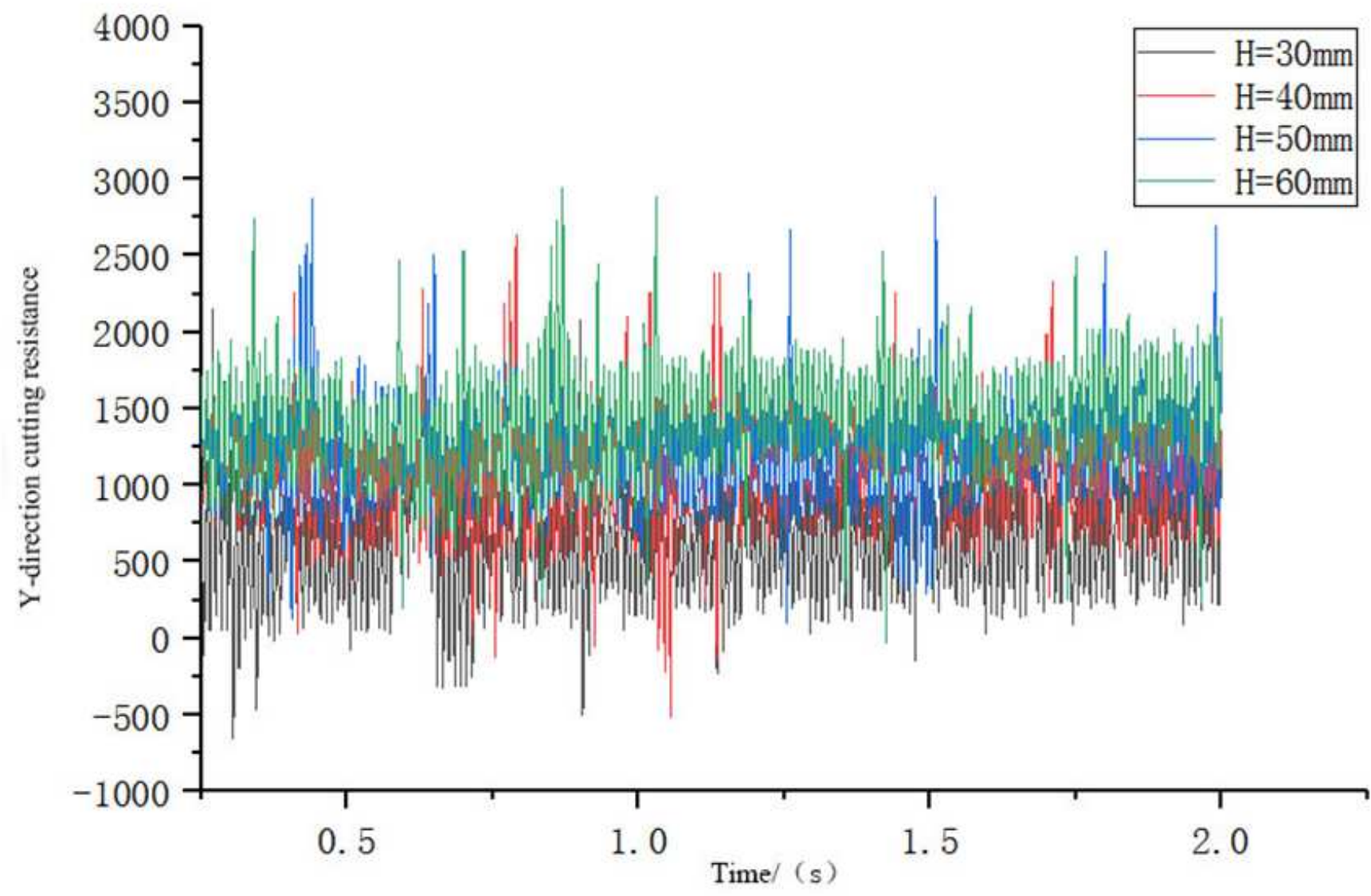

Figure 20

Y-direction cutting force at different depths of cut 

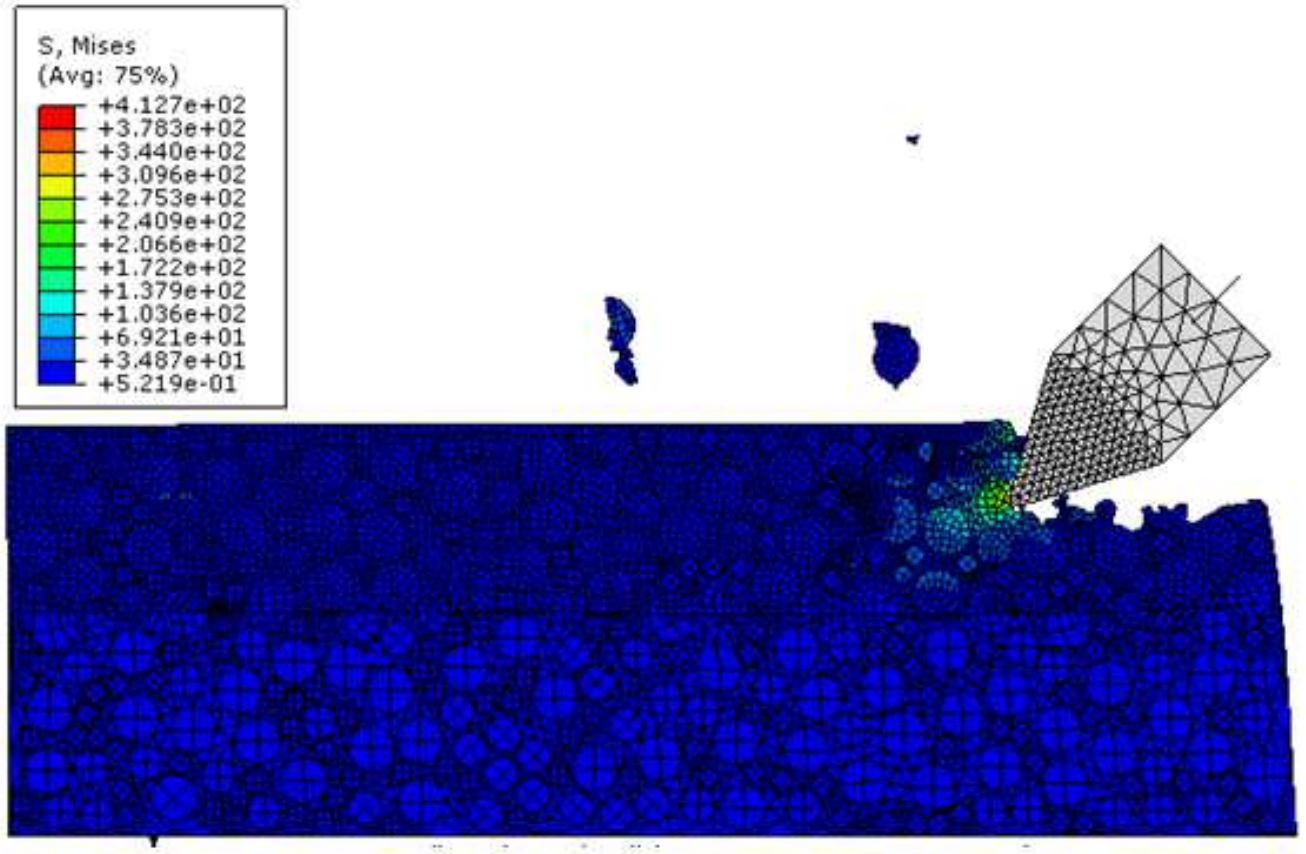

(a)

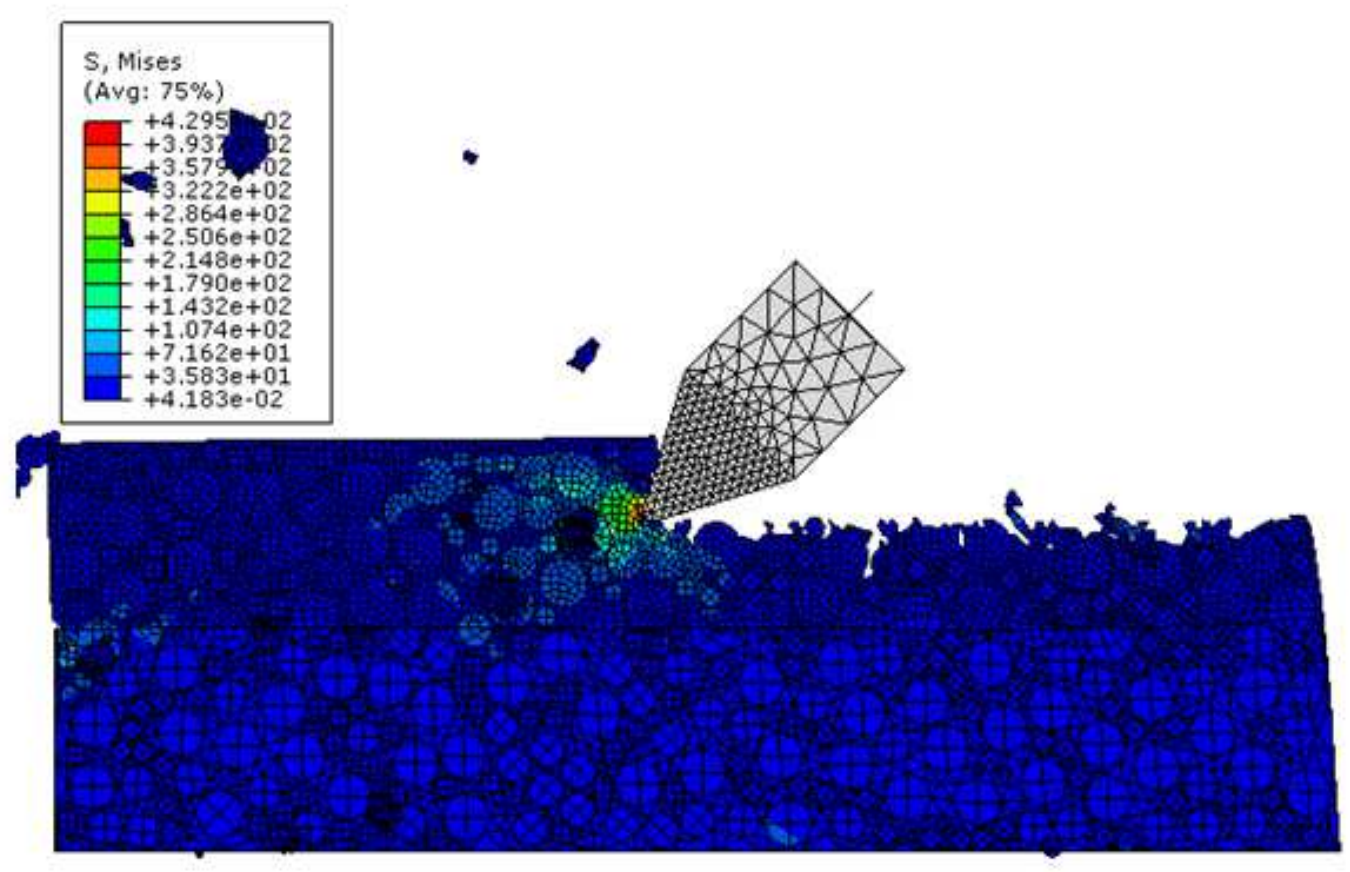

(b)

Figure 21

Schematic diagram of working process at different feed rates: (a) v=100(mm/s), (b) v=400(mm/s) 


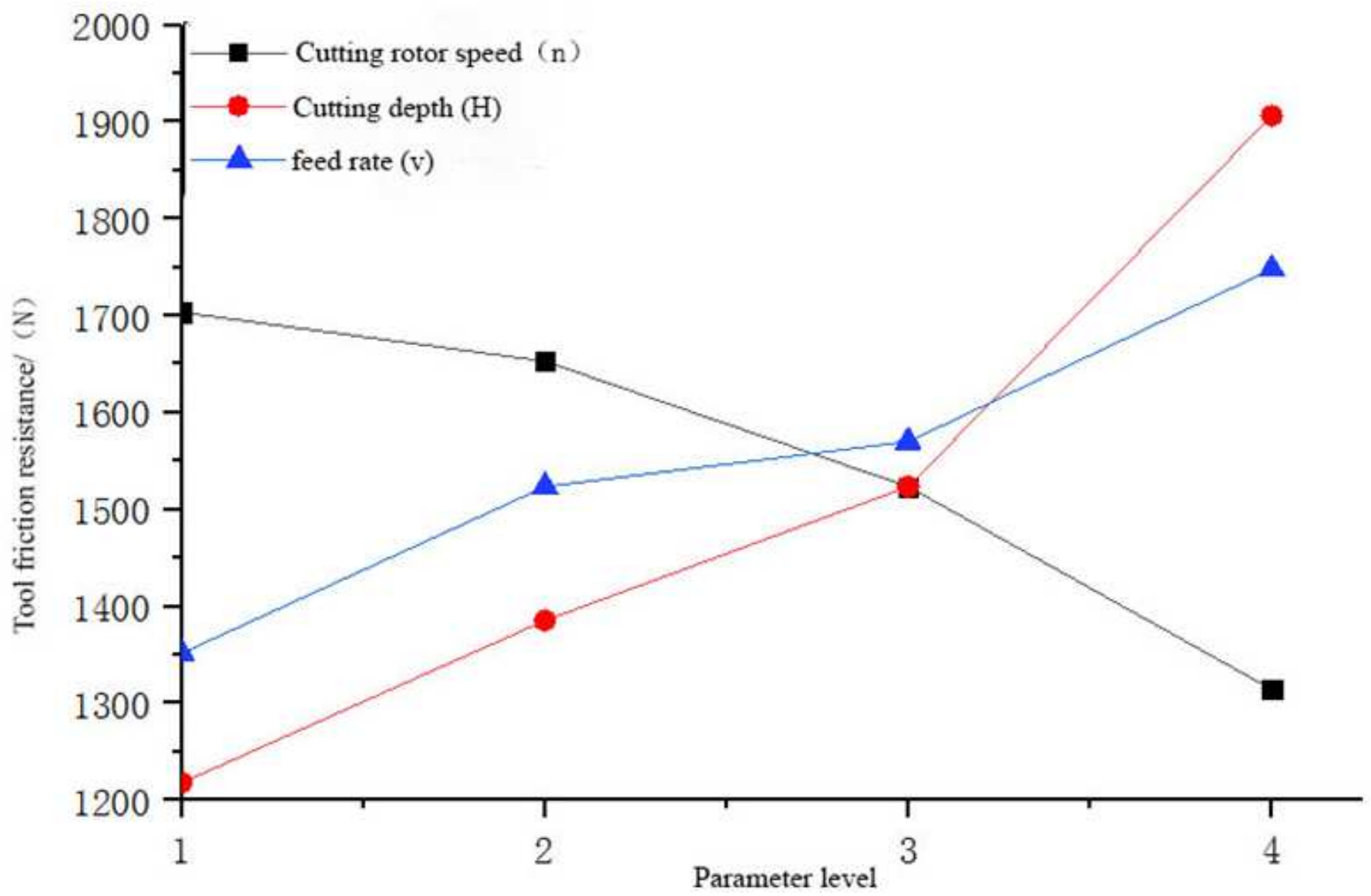

Figure 22

Variation trend of tool friction resistance with parameter grade 


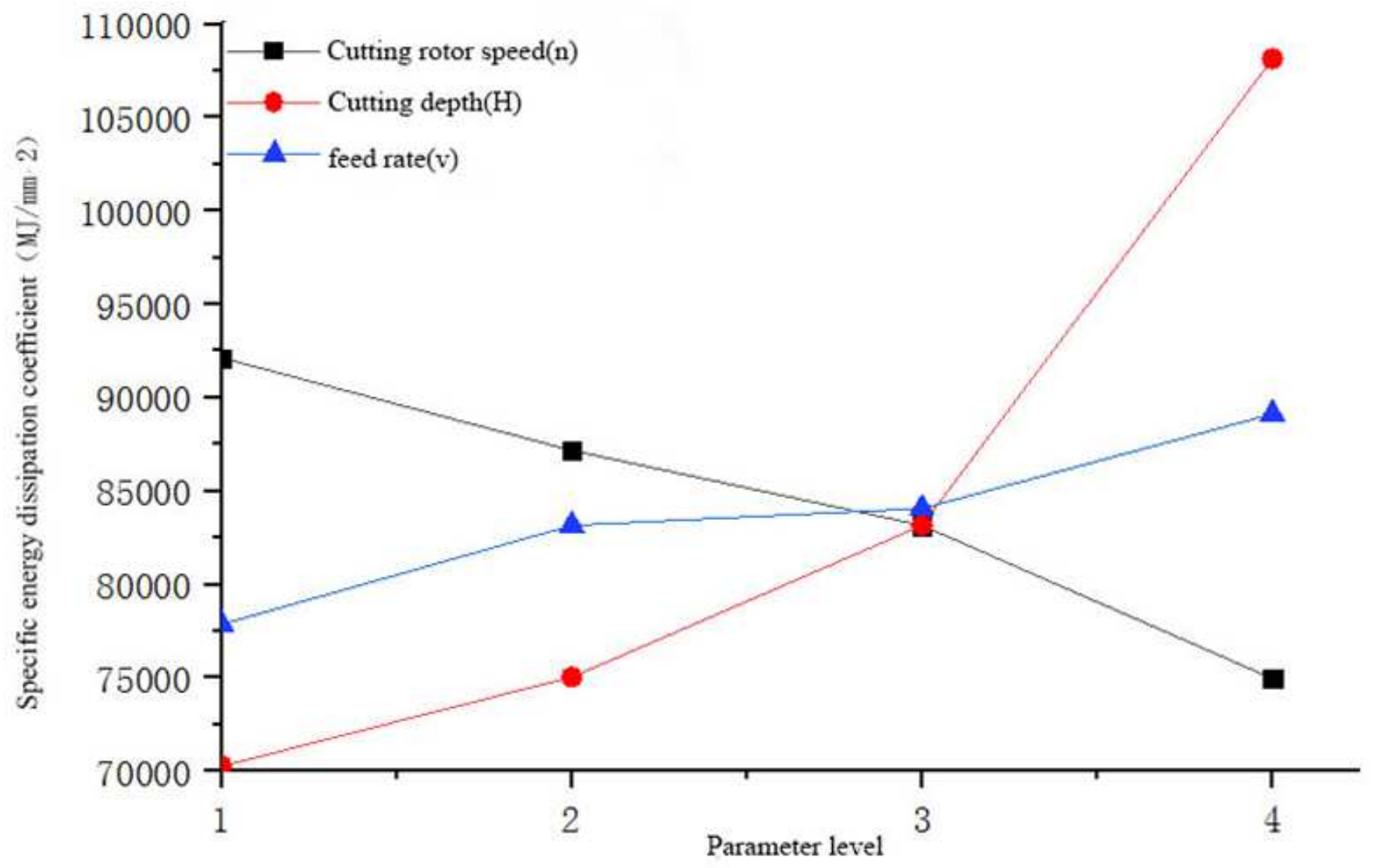

Figure 23

Variation trend of specific energy dissipation coefficient with parameter grade

\section{Supplementary Files}

This is a list of supplementary files associated with this preprint. Click to download.

- table1017.doc

- table19.doc 